Rochester Institute of Technology

RIT Scholar Works

Theses

8-8-2017

\title{
An Exploration of Rhythm Perception in African Penguins (Spheniscus demersus)
}

Irene A. Fobe

iaf8034@rit.edu

Follow this and additional works at: https://scholarworks.rit.edu/theses

\section{Recommended Citation}

Fobe, Irene A., "An Exploration of Rhythm Perception in African Penguins (Spheniscus demersus)" (2017). Thesis. Rochester Institute of Technology. Accessed from 


\title{
An Exploration of Rhythm Perception in African Penguins
}

\section{(Spheniscus demersus)}

\author{
by \\ Irene A. Fobe
}

\begin{abstract}
A Thesis in
Experimental Psychology

Submitted in Partial Fulfillment of the Requirements for the Degree of Master of Science
\end{abstract}

August $8^{\text {th }}, 2017$ 
We approve the thesis of Irene A. Fobe:

Dr. Caroline M. DeLong Date

Associate Professor, Dept. of Psychology, RIT

Faculty Advisor and Chair of the Thesis Committee

Dr. Andrew Herbert

Date

Professor, Dept. of Psychology, RIT

Reader

Dr. Kirsten Condry

Date

Associate Professor, Dept. of Psychology, RIT

Reader 


\section{Acknowledgements}

First of all, I would like to thank Dr. DeLong, my dedicated thesis advisor. This process has been rewarding and not nearly as stressful as I imagined it would be, thanks to you. Thanks for spending hours with me to design my procedure, and even more hours on top of that reading my drafts and providing feedback. I would like to also thank the other two members of my thesis committee, Dr. Condry and Dr. Herbert. Dr. Condry, thank you for helping with the design of the method. Your input on the habituation-dishabituation methodology made this experiment possible. Dr. Herbert, thank you for your direct and helpful edits to my thesis proposal, and your all-around support throughout the process of completing my thesis.

I also sincerely thank the staff at the Seneca Park Zoo; especially the curator David Hamilton, and the penguin keepers Kevin Blakely, Kellee Wolowitz, and Hanna Kaiser. Thank you, Peter Cook, for giving me advice on how to design my experiment. I would like to thank Tyler Wilcox for helpful suggestions for the statistical analyses of my test data. I would also like to mention a few very special penguins. Sky, thank you for making me smile every time you stepped on my shoe, untied my boots, or followed me around the penguin habitat during set up. Obi, thank you for never leaving my sneakers tied at the end of equipment set up. Blanka, thank you for looking out for all the other penguins and making sure all your non-biological chicks are safe. Gizmo, thanks for the great picture, you are very photogenic and that shot will forever hold a place on my desk in a frame. 


\begin{abstract}
Rhythmic properties in penguin vocalizations may be unique to individuals. Rhythm perception is a cognitive ability previously thought to be exclusive to vocal-learning species who have the neurological complexities required to mimic conspecific and heterospecific vocalizations. Discovering rhythm perception in penguins would provide insight on penguins' ability to recognize kin using auditory cues, and discount theories constraining rhythm perception to vocal-learning animals. The goal of this study was to learn if African penguins (Spheniscus demersus) could perceive changes in rhythm using a habituation-dishabituation paradigm. Subjects were 32-38 African penguins housed at the Seneca Park Zoo in Rochester, NY. Penguins were presented with four rhythms at $4 \mathrm{kHz}$ and head turns per bird were counted in 24 sessions. Each session was composed of ten familiarization trials followed by six test trials that alternated between the familiar and novel rhythm. The number of head turns per bird did not significantly increase from the last three familiarization trials to the first novel test trial. Results did not provide evidence for auditory rhythm perception in penguins. This may be because subjects met the habituation criterion in only 9 out of 24 sessions or because of other limitations of the method. It is also possible that a habituation-dishabituation methodology was not ideal for discovering rhythm perception in penguins. More research on auditory rhythm perception in penguins is needed.
\end{abstract}


Table of Contents

Acknowledgements

Abstract $\quad$ iv

$\begin{array}{lr}\text { Introduction } & \mathbf{1 - 2 6}\end{array}$

The Importance of Rhythm Perception ........................................................ $6-9$

Rhythm Perception in Non-Human Animals ..................................................... $9-14$

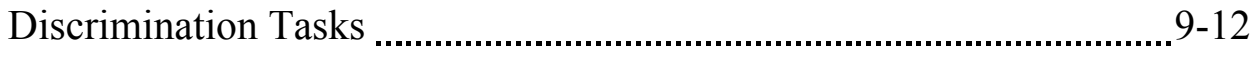

Production and Entrainment ...........................................................12-14

Habituation-Dishabituation Methodology ..................................................... 14-20

Human Infant Studies ............................................................... 14-16

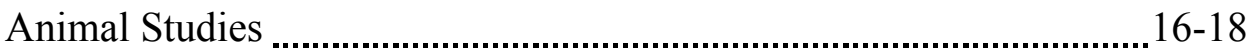

Group Habituation ......................................................................... 18-20

Sound Perception and Production in the African Penguin $\ldots \ldots \ldots \ldots \ldots \ldots \ldots \ldots \ldots \ldots \ldots . . . . . . . . . . . . .20-24$

Sound Perception .......................................................................20-22

Sound Production ........................................................................22-24

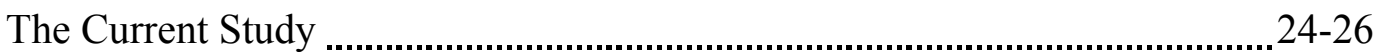

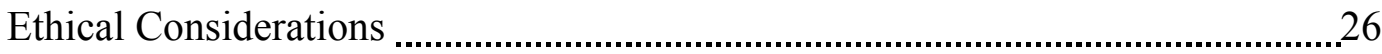

$\begin{array}{lr}\text { Method } & \text { 26-34 }\end{array}$

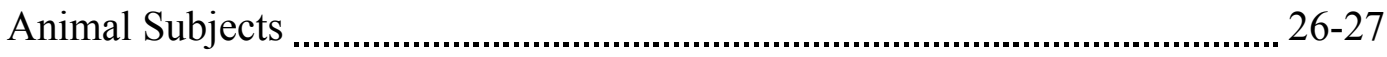

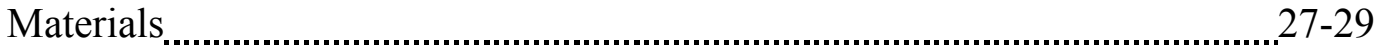

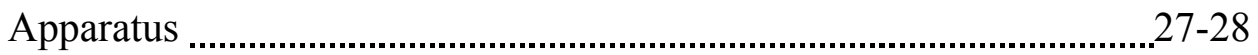

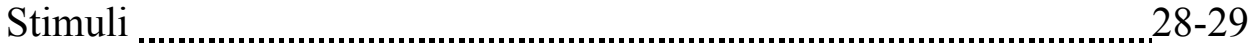

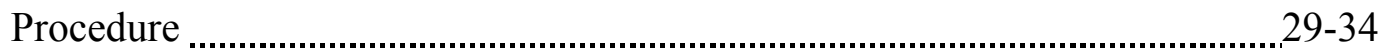


Pilot Study 29-32

Test Sessions 32

Video Coding . $32-33$

Inter-Rater Reliability.. $33-34$

Results 34-37

Familiarization Trials 35

Transition from Familiarization Trials to First Novel Test Trials $35-37$

Test Trials 37

Discussion 38-44

Conclusion 44

References

45-53

Tables

54-65

Figures

66-78

Appendix

79 
An Exploration of Rhythm Perception in African Penguins (Spheniscus demersus)

Rhythm can be broadly defined as a sequence of sounds with a temporal pattern that repeats over time (Hulse, Takeuchi, \& Braaten, 1992; Mercado \& DeLong, 2010; Trehub \& Thorpe, 1989). Humans and some non-human animals can perceive and/or produce rhythms (Patel, 2006). Rhythm perception or production has been seen in non-human animals both in the wild and in a laboratory setting. For example, in their natural habitats, songbirds and crickets incorporate rhythmic properties into mating rituals (Saar \& Mitra, 2008; Wagner \& Reiser, 2000). In laboratory studies, rhesus monkeys have been trained to tap rhythmically (Merchant \& Honing, 2014), starlings were trained discriminate between multiple rhythmic stimuli (Hulse, Humpal \& Cynx, 1984) and bottlenose dolphins have been shown to be able to perceive and produce rhythms (e.g., Harley, Crowell, Fellner, Odell, \& Larsen-Plott, 2005; Harley, Odell, Putnam, Goonen, \& DeLong, 2002).

The perception of rhythm is presumed to be adaptive. It is thought that musicality in animals, which includes rhythm, plays a valuable role in mate selection, offspring soothing, and group cooperation in synchronous tasks (Honing, ten Cate, Peretz, \& Trehub, 2015). Rhythm perception may also be important to penguin species in identifying related individuals based on rhythmic differences in vocalizations (Favaro, Gamba, Alfieri, Pessani, \& McElligott, 2015; Thumser \& Ficken, 1998). Rhythm sensitivity is central to the acquisition of language in humans. Prosody, which is the combination of intonation and rhythm in vocal utterances, helps human infants acquire the rhythmic nature of their native language very early in life (Demuth, 1996; Nazzi et. al, 1998; Ramus, Hauser, Miller, Morris, \& Mehler, 2000). Examples of rhythmic behavior can be found broadly in non-human species. Female field crickets, for example, prefer to mate with males with a faster chirp rate (Wagner \& Reiser, 2000). When 
defending territory, groups of rattan ants synchronize their alarm signals to shake vines that their competing neighbors are sitting on (Merker, Madison \& Eckerdal, 2009). The ability to perceive regular temporal patterns seems to be adaptive, therefore, investigating rhythm perception in a controlled situation is important.

The current study examines auditory rhythm perception in the African penguin (Spheniscus demersus). Penguins rely heavily on auditory signals to locate and recognize their kin in large, noisy breeding colonies while other birds are vocalizing, and sound is readily attenuated by penguin bodies (Aubin 2004; Aubin \& Jouventin, 2002; Favaro et al., 2015), this makes them a good subject to study for rhythm perception. Penguins' use of auditory cues to recognize kin (Clark, Boersma, \& Olmsted, 2006). The mechanism behind auditory kin recognition in penguins is still unknown, however, it seems rhythm perception may be involved. Penguins have a variety of vocalizations, many of which have stereotypical rhythmic patterns.

Rhythm is an ideal medium to communicate information in a noisy penguin colony. Rhythms are consistent and redundant which is helpful in localizing a sender of a call (Aubin, 2004). Rhythms are also robust across long distances, unlike other acoustic parameters such as frequency. Aubin, Joventin, and Hildebrand (2000) showed that frequency modulations with rhythmic patterns in amplitude were not as drastically altered over long distances (1,8 and $16 \mathrm{~m})$ as were frequency/amplitude modulations lacking a rhythmic component (the sound remained intact at $1 \mathrm{~m}$ but was drastically altered in period duration at 8 and $16 \mathrm{~m}$ ).

African penguins, the subjects of the current study, belong to the group of the northernmost distributed penguins belonging to the genus Spheniscus. This group also includes Magellanic (S. magenallicus), Humboldt (S. humboldti), and Galapagos penguins ( $S$. mendiculus), all of which have vocalizations that are similar across these species in structure and 
function. A playback study with Magellanic penguins, the African penguin's closest relative (Ksepka, Bertelli, \& Giannini, 2006), revealed that adults could identify their mates, and chicks could identify their parents using only auditory cues (Clark et al., 2006). Another study that examined the structure of Magellanic, Humboldt, and African penguin calls extracted statistically significant individual differences in a handful of rhythmic parameters. Within each species, individuals showed significant differences in number of syllables (S. humboldti \& $S$. demersus), duration of the longest syllable (S. humboldti, S. demersus, \& S. magellanicus), total call duration (S. humboldti) and sum of inter-syllable interval duration (S. humboldti, \& S. magellanicus; Thumser \& Ficken, 1998). Rhythmic signatures in the penguins' vocalizations in the genus Spheniscus may contribute to their ability to recognize one another using auditory cues (Favaro et al., 2015).

Until recently, researchers asserted that only a handful of non-human species, deemed "vocal-learners", had the cognitive ability to perceive rhythm (Patel, Iverson, Bregman, Schultz, 2009; Schachner, Brady, Pepperberg \& Hauser, 2009). This list includes three groups of birds (songbirds, parrots, and hummingbirds), cetaceans, and pinnipeds including many seal species (Leptonychotes weddelli; Hydrurga leptonyx; Erignathus barbatus, Phoca vitulina, \& Pagophilus groenlandicus) and walruses (Odobenus rosmarus; Feenders, 2008; Patel, 2006; Reichmuth \& Casey, 2014). Vocal learners are species with plasticity in their sound production which enables them to engage in complex communication (Reichmuth \& Casey, 2014). Vocallearning species imitate vocalizations of conspecifics and heterospecifics by modifying acoustic and syntactic sounds with their vocal organs. For example, a bullfinch could imitate a 45 -note folk song from a human tutor (Hoeschele, Merchant, Kikuchi, Hattori, \& Cate, 2015). Penguins are considered non-vocal learning animals as they do not fall within the three clades of birds 
(songbirds, parrots, and hummingbirds) that have evolved this specific ability to vocally mimic sounds (Schachner et al., 2009). There is also no evidence in the literature of penguins imitating vocalizations. If the current study reveals that African penguins can perceive rhythm, it could add to the body of research supporting the perception of rhythm in non-vocal-learning species. This could reveal that rhythm perception in non-human animals is more widespread in nonhuman animals than the current literature states (Wilson \& Cook, 2016).

African penguins' vocalizations and the information they carry are important to social recognition, and ultimately the survival of their species (Favaro et al., 2015). Understanding acoustic features like rhythm that may be important to African penguins for communication with mates and offspring could help humans engage in more effective conservation practices. African penguins are listed as endangered on the International Union for Conservation of Nature Red List (African penguin Spheniscus demersus, n.d.) . Their population declined by over $60 \%$ from 2001 to 2009 (Parsons, Schaefer \& Vanstreels, 2016; Sherley et al., 2013). The reason for this population decline is due mostly to low food availability, and breeding success that is inadequate to sustain their population (Crawford et al., 2003). Spheniscus penguins are also frequently entangled and killed in fishing gear (Cardoso, Bugoni, Mancini, \& Haimovici, 2011; Majluf, Babcock, Riveros, Schreiber, \& Alderete, 2002). Learning about a species’ perceptive and cognitive abilities provide us with tools to conserve them in their natural habitat (Laiolo, 2010). If we learn the that the perception of rhythm is involved in African penguin vocal recognition, we could develop guidelines and policies to minimize anthropogenic noise that may be disruptive to the perception of rhythmic patterns present in African penguin calls so as not to disturb their breeding success. 
We could also develop conservation tools such as pingers (small devices attached to fishing nets to deter non-target species by producing tones). Pingers may be an effective solution to reduce bycatch of penguins. Pingers are often used to deter non-target species from nets by playing an isochronous tone, either constantly, or when an animal approaches fishing gear. Currently, there is no evidence supporting that pingers are used to deter penguins from fishing nets, however, pingers used to deter other marine animals could incidentally deter penguins. Pingers have successfully reduced bycatch induced mortality of marine including Franciscana dolphins (Pontoporia balinvillei; Bordino et al., 2002), harbor porpoises (Phocoena phocoena; Kraus, 1997), short beaked-common dolphins (Delphinus delphis; Barlow \& Cameron, 2003), California sea lions (Zalophus californianus; Barlow \& Cameron, 2003) and the common murre (who occupy the same ecological niche as penguins; Melvin, Parrish \& Conquest, 1999).

The perception of rhythm in African penguins has not yet been studied in controlled laboratory conditions. The habituation-dishabituation method was chosen for the current study. The habituation-dishabituation method is widely used to test auditory and visual discrimination in infants (e.g., Kavsek \& Borstein, 2010; Trehub, 1987). This method is ideal because it capitalizes on naturally occurring behaviors, such as a participant's likelihood to turn towards the source of a novel acoustic stimulus. The utilization of innate reactions to stimuli is beneficial when working with non-verbal participants (Trehub, 1987). For this reason, the habituationdishabituation method has also been used to examine auditory discriminations in animals (e.g., Fischer, 1998; Maros et al., 2008; Ramus et al., 2000). An advantage of the habituation/dishabituation method is that it can be used without the need for laborious and timeconsuming animal training. Although a habituation-dishabituation paradigm has not yet been used to study discrimination abilities in penguins under controlled conditions, some studies have 
observed habituation in wild penguin colonies to disruptive stimuli such as human presence and overhead helicopter flights (Fowler, 1999; Hughes, Walunda, Stone, Ridout \& Shears, 2008).

In the following sections, I will first discuss the importance of rhythm perception, then I will discuss studies that focused on rhythm perception in animals. Next, I will review studies using a habituation-dishabituation method to learn about auditory discrimination in infants and non-human animals. Finally, I will outline what is known about sound perception and production in my subjects, African penguins.

\section{The Importance of Rhythm Perception}

There are many theories supporting the perception of rhythm as an adaptive ability. Rhythm perception provides individuals with the ability to predict the timing of stimuli in their environment which allows them to effectively interact with their surroundings. Larsson (2012, 2014) proposes that the ability to perceive and the regular timing breathing and locomotion (walking, trotting, swimming) of others in group allow individuals to synchronize the timing their actions to that of the group. This reduces acoustic masking of important auditory cues, such as the approach of a predator or the call of a juvenile.

Ravignani, Bowling, and Fitch (2014) propose a handful of benefits individual animals can gain by synchronizing their vocalizations or locomotion to those of others in a group (referred to chorusing). These benefits include higher chances of attracting mates (due to female preference of group vs. individual signalers; Morris, Kerr, \& Fullard, 1978), the ability to acoustically "blend into the crowd" to avoid predation, and even the ability to use synchronized motor movements to accomplish a goal (e.g., a group ants synchronize their alarm calls to shake vines that they are sitting on to startle competing neigbors; Merker, et al., 2009). 
In humans, prosody is the perception of rhythm and intonation in human speech. It is fundamental to our ability to learn language (Nazzi et. al, 1998; Ramus, Hauser \& Mehler, 2000; Demuth, 1996). The perception of rhythm could also be important for animal communication as well. If animals can perceive rhythm, they can use complex temporal patterning to convey different kinds of information (Marisa, Merchant, Kikuchi, Hattori, \& ten Cate, 2015). For example, African penguin vocalizations that differ in rhythmic structure are used in different circumstances and penguins react to them differently. The contact call is a single syllable and is used both by the receiver to locate the signaler in a crowd. In contrast, the ecstatic display song is composed of up to $12-13$ syllables of different durations and is signaled in in a very different circumstance (to advertise territory and attract mates; Favaro et al., 2015). It would make sense if future research reveals that penguins perceive changes in rhythm. After all, expending energy to produce rhythmic vocalizations would be wasteful if the vocal elaborations are not perceived by conspecifics.

Although rhythm perception is adaptive, some researchers believe rhythm perception is unique to vocal-learning species who are capable of flexible vocal mimicry of sounds produced by conspecifics and heterospecifics (like songbirds, parrots, dolphins and elephants; Patel et al., 2009; Schachner et al., 2009), many studies have shown strong evidence for rhythm perception in non-vocal learning animals such as California sea lions and non-human primates and even rats (Cook et al., 2013; D’Amato \& Salmon, 1982; Hattori et al. 2013; Large \& Gray, 2013; Merchant \& Hoening, 2014).

If many non-vocal learning animals are found to perceive rhythm, it is not unreasonable hypothesize that penguins can perceive changes in rhythm as well. As evidence for rhythm perception in non-vocal learning animals grows, it could change our understanding of the 
mechanism for rhythm perception in the brain and the ecological adaptiveness of rhythm in the animal kingdom. Until recently, it has been proposed that only vocal-learning animals possess genuine rhythm perception. This Vocal Learning Theory proposes that rhythmic abilities exist as a bi-product of the structural couplings of auditory and motor areas in their brains. Evidence for the Vocal Learning Theory stems from functional imaging evidence that sequential and temporal processing and rhythmic behaviors originate in the motor cortico-basal ganglia-thalamo-cortical circuit (mCBGT; Grafton Hatzeltine \& Ivry., 1995; Grahn \& Brett, 2007; Harrington, Zeibelman, Hinton, \& Rao., 2010; Wiener, Turkeltaub, \& Coslett, 2010; Merchant \& Honing, 2014) an area of the brain which is also associated with vocal learning (Doupe, Perkel, Reiner, \& Stern, 2005; Patel, 2006). This exclusive theory of rhythm perception undermines the possibility that non-vocal learners perceive rhythm, even though rhythm perception may be important in behaviors such as mating, communication and group cooperation, for a wide range of animal species (Phillips-Silver, Aktipis \& Bryant, 2010; Wilson \& Cook, 2016).

An alternative hypothesis for rhythm perception proposes the ability to perceive rhythm is a result of neural oscillations in the brain created by repeated sensory input (Wilson \& Cook, 2016; Large, 2008). Neural oscillations occur when groups of neurons in the brain collectively fire in response to external auditory stimuli (Large, 2008). These neural signals entrain to the sensory input resulting in the ability to anticipate the timing of future sensory input (Bispham, 2006). When rhythmic stimuli are sensed, the timing of neuronal activity aligns with the timing of the stimulus (Wilson \& Cook, 2016). Synchronized neuronal firing in response to rhythmic stimuli has been shown in humans, macaques and zebrafish. (Lakatos, Karmos, Mehta, Ulbert, \& Schroeder, 2008; Saleh, Reimer, Penn, Ojakangas, \& Hatsopoulos, 2010; Sumbre, Muto, Baier, \& Poo, 2008). The neural oscillation based theory of rhythm perception presents rhythm 
perception as a widespread cognitive ability in non-human animals that potentially relies on simple neurological mechanism that occurs in all animal brains (Wilson \& Cook, 2016).

\section{Rhythm Perception in Non-Human Animals}

Rhythm perception has been studied in many non-human animal species, such as rhesus monkeys, rats, and pigeons (non-vocal learners), and bottlenose dolphins, finches, and starlings (vocal learners). A variety of methods have been used to study rhythm perception in animals. One widely used methodology that focuses on rhythm perception is training an animal on a discrimination task. In these types of tasks, an animal's ability to discriminate between stimuli with different temporal structures can give insight on how animals perceive rhythm (e.g., Damato \& Salmon, 1982; Harley, Odell, Goonen, \& DeLong, 2002, Hulse et al., 1984). Another method that has gained popularity in the study of rhythm perception is the objective analysis of animals' ability to align motor movements with a rhythmic stimulus, or produce different rhythms (e.g., Cook et al., 2013; Harley et al., 2005; Hattori, Tomonaga, \& Matsuzawa, 2013; Large \& Gray, 2015). In these tasks, animals either spontaneously, or through reinforcement training, align motor movements with a background auditory rhythmic stimulus (entrain), or produce rhythms with their motor movements in response to a particular discriminatory stimulus.

Discrimination tasks. Many trained discrimination tasks to test rhythm perception in animals have been conducted with birds. Understanding rhythm perception in bird species is relevant to the current study because penguins are birds. Hulse et al. (1984) studied rhythm perception in European starlings (Sturnus vulgaris). This research revealed that European starlings could discriminate between rhythmic and arrhythmic stimuli and two different rhythmic stimuli at a variety of tempos. Arrhythmic stimuli are sounds with persistent random tone and intertone intervals. The starlings were trained on a discrimination task until they were 
consistently discriminating between either the rhythmic and arrhythmic, or the two rhythmic stimuli; then novel tempos were introduced. All birds generalized the rhythmic/arrhythmic and the rhythmic/rhythmic discrimination significantly above chance over all tempos except for the slowest two tempos which had been multiplied from the original tempos by factors of 2 and 1.6. These results implied that the starlings were using information found in the rhythmic structure of the stimuli to make their discriminations.

Rhythm perception has also been studied in pigeons. Hagmann and Cook (2010) used a go/no-go procedure to learn whether pigeons could discriminate between rhythmic and arrhythmic stimuli as in Hulse et al.'s (1984) study. Instead of using a single stimulus set like Hulse et al. (1984), they trained birds to respond to, or ignore multiple exemplars of rhythmic and arrhythmic stimuli generated with sounds from different instruments (e.g., a cymbal and a snare) at four different tempos $(100,120,140$, and $180 \mathrm{bpm})$. They found that when a single exemplar was used pigeons could discriminate between rhythmic and arrhythmic sounds. However, when there were multiple exemplars pigeons were unable to discriminate rhythmic and arrhythmic stimuli. Results revealed pigeons could not categorize the rhythmic and arrhythmic stimuli when multiple exemplars were used indicating they may not have a conceptual grasp of the difference between rhythmic and arrhythmic auditory stimuli.

Aa, Honing, and ten Cate (2015) conducted a similar multiple-exemplar study with zebra finches. Aa et al. (2015) used a go/no-go procedure to test the ability of zebra finches to discriminate between isochronous rhythmic stimuli and arrhythmic stimuli. An isochronous stimulus is one composed of equal tone and inter-tone intervals. They found that finches could discriminate between the rhythmic and arrhythmic training stimuli, but could not generalize the discrimination across tempos. When training with three tempos was attempted, finches were still 
unable to generalize the discrimination across tempos. Researchers concluded that finches were sensitive to the rhythmic structure of stimuli; however, the finches were not able to categorize all isochronous or all arrhythmic stimuli into two distinct groups. In summary, different levels of rhythmic abilities have been seen across bird species. Starlings and finches (vocal learners) could discriminate between stimuli differing in temporal structure when a single exemplar was used in training and testing. Pigeons (non-vocal learners), who were only trained with multiple exemplars, failed to discriminate rhythmic stimuli from arrhythmic stimuli. More evidence on rhythm perception in non-vocal learning birds is needed.

Discrimination studies have also been used to understand rhythm perception in terrestrial and marine mammals. D'Amato and Salmon (1982) found that monkeys (Cebus appella) and rats (Rattus norvegicus) could perceive differences between two tunes varying in pitch and in rhythm in a discrimination task. The discrimination transferred when stimuli were shifted by one octave but not by two octaves, a discrimination that is difficult for humans as well. This study revealed rhythm and pitch were used by rats and monkeys to discriminate between the two melodies. In a second experiment, D'Amato and Salmon (1982) aimed to learn if patterns in frequency or rhythm were more important discriminatory cues to rats. They tested rats' ability to discriminate between continuous tones varying from one another only in pattern of frequency, and tones differing from one another only in rhythm. They found that rats acquired the discrimination of the tones differing in rhythm more readily than they acquired the discrimination of the tones differing in frequency patterning. Rats also showed greater generalization to rhythmic stimuli over frequency-modulated stimuli when the intensity of the stimulus was changed. This revealed that rhythm played some role in the rats' ability to discriminate stimuli and determined if that sound would be generalized across intensities. 
Bottlenose dolphins (Tursiops truncatus) have also been shown to perceive rhythm. Harley et al (2002) trained a dolphin to respond to six different rhythms with a different behavior (e.g., a spin, or a wave). For example, if the dolphin heard Rhythm A, they would be trained to respond with a pectoral wave for a food reward, if the dolphin heard Rhythm B, they were reinforced for spinning. In test sessions, the dolphin successfully produced the correct behavior for all six rhythms with an accuracy of 94\%. The dolphin's discrimination performance remained intact ( $93 \%$ accuracy) when the stimuli were shifted in frequency or tempo suggesting that the dolphin was attending to temporal patterning of the rhythm independent of absolute pitch or tempo of the tones meaning perhaps dolphins process rhythmic information separately from pitch or tempo.

Production and entrainment. Discrimination tasks are useful in studying rhythm in animals, however, rhythm in animals can also be examined in studies that aim to learn if animals can produce, or align their motor movements (entrain) to rhythm. Studies on rhythm production and entrainment to rhythm in non-human animals are relevant to my research as they capitalize on the observation of animal's reactions to changes in rhythmic stimuli. Animals from a variety of taxa have been shown to entrain to or produce rhythm.

Many vocal-learning birds can entrain to a rhythmic background stimulus. A sulfurcrested cockatoo (Patel et al., 2009), an African grey parrot (Schachner et al., 2009) and budgerigars (Hasegawa, Okanoya, Hasegawa \& Seki, 2009), were able entrain head bobbing (cockatoo and African grey) and pecking (budgerigars) to various rhythms. Many non-human primates and bottlenose dolphins have also been shown to entrain or produce rhythms (Harley et al., 2005; Hattori et al., 2013; Large \& Gray, 2015; Merchant \& Hoening, 2014) . Macaque monkeys have been seen to respond to and produce rhythms (Merchant \& Hoening, 2014). 
Bonobos and chimpanzees have been shown to align their motor movements to beats (Hattori et al., 2013; Large \& Gray, 2015).

Merchant and Hoening (2014) discuss that macaques in have the biological ability to produce sequences of temporal tapping motions with their hands; they can match tempo of tonal metronomic sounds with their movements, yet consistently lag behind the phase of the sound by approximately $50 \mathrm{~ms}$ (Zarco, Merchant, Prado \& Mendez, 2009). Macaques also changed the direction of their gaze and the position of their eyebrows when experimenters exposed them to rhythmic and arrhythmic stimuli in a paradigm where a rhythmic stimulus was presented repetitively followed by a delay, and then a series of arrhythmic stimuli (Selezneva et al., 2013). Macaques, however, are unable to tap in synch with a rhythm even after a year of training. Merchant and Honing suggest that this is because of the lack of a strong coupling between the auditory and motor system in these animals that is characteristic of vocal learning species (humans, some birds, cetaceans, seals, walruses and elephants). This claim, however, may not be sound.

Although macaques have not yet been shown to entrain to rhythms, other non-vocallearning primates were shown to entrain motor movements to rhythms in empirical studies. Ai, a chimpanzee (Pan troglodytes), was trained to entrain her tapping of two piano keys to a background "distractor" isochronous beat (Hattori et al., 2013). Kuni, a bonobo (Pan paniscus), was shown to entrain drum hitting episodes to a background metronome at a variety of tempos, or rates of presentation (Large \& Gray, 2015).

Marine mammals have been shown to perceive rhythm through entrainment and production-based experiments as well. Cook, Rouse, Wilson and Reichmuth (2013) found that a California sea lion named Ronan could entrain to multiple sounds including metronomic tones 
and pop songs. She was presented with a variety of stimuli from frequency-modulated and metronomic tones to the song "Boogie Wonderland" over a range of tempos (72-137 bpm). Statistical analyses revealed that the timing of Ronan's head bobs was not significantly different from the timing of the nearest beat in the auditory stimuli showing that Ronan had entrained to the beats. A follow up study found that Ronan's entrainment showed human-like beat keeping responses to shifts in phase and tempo in rhythmic stimuli (Rouse, Cook \& Reichmuth, 2015). A phase shift is when the initiation of beats in a rhythmic stimulus is shifted either forward or backwards in time relative to an original or baseline phase. Entrainment to rhythm can indicate rhythm perception in animals, but so can rhythm production. A bottlenose dolphin was trained to produce six rhythms vocally in response to specific objects (Harley et al., 2005; Harley, Fellner, Odell \& Putnam, 2005). Distinct rhythms are also a major component of bird songs (Saar \& Mitra, 2008).

To entrain to or produce rhythms, one must be able to perceive the rhythm (Merchant \& Hoening, 2014; Patel 2006). Because entrainment and rhythm production have been seen across many different species, one can hypothesize that the perception of rhythm is adaptive and that perhaps more non-human animals are capable of the perception of rhythm than previously believed (Wilson \& Cook, 2016).

\section{Habituation-Dishabituation Methodology}

Human infant studies. Habituation-dishabituation methods have been used extensively in developmental psychology (for a review see Kavsek \& Bornstien, 2010). They are most often used to study visual discrimination, where the dependent variable is the time an infant spends visually fixated on a particular stimulus (Kavsek \& Bornstien , 2010). When something is interesting to infants, they visually fixate on it for longer. When something is no longer 
interesting to infants, they look at it for less time. Habituation-dishabituation methods have also been used to test infants' auditory perception. A break in visual fixation happens when infants stop attending to something, and can be quantified by measuring eye movement or head turning which is indicative of dishabituation. I will focus on reviewing studies that have used the habituation-dishabituation method with auditory rhythmic stimuli, since these types of stimuli are used in the current study.

Pickens and Bahrick (1995) found that seven-month-old infants could discriminate between bimodal (auditory and visual) presentations of stimuli varying in rhythm (defined as sounds with a characteristic pattern over time), across different tempos. Pickens and Bahrick (1995) came to these conclusions by first habituating infants to a rhythm at a particular tempo. Once the habituation criterion was met, and an infant's eye fixation decreased to $50 \%$ or more below an established baseline fixation, test trials began. Once infants were habituated to the familiar stimulus, three presentations of either the familiar stimulus or a novel stimulus that differed from the familiar stimulus in rhythm or tempo were played. Dishabituation was detected by comparing the mean visual fixation time in test trials to their individual subjects' visual fixation in familiarization trials. If the mean fixation was significantly higher in novel test trials, dishabituation occurred. Results revealed that infants dishabituated to stimuli with a different rhythm, but not tempo. These findings suggest that infants perceived rhythms played at a novel tempo as "the same" and stimuli with different rhythm as "different."

Lipton and Spelke (2003) used head turning as a dependent variable to learn if infants could discriminate between large approximate numerosities in auditory sequences in a habituation-dishabituation procedure. Infant were familiarized to either a large or smaller number of sounds (e.g., bells, whistles, chirps) over the course of twelve trials followed immediately by 
six test trials. Test trials alternated between the familiar stimulus and a novel stimulus. The novel stimulus had greater or fewer sounds in a sequence than the familiar stimulus and the order of test trials (novel or familiar first) was counterbalanced for each condition. The results of this experiment revealed that six-month-old infants could discriminate between sixteen and eight sounds, but not twelve and eight sounds. Nine-month-old infants could discriminate between twelve and eight sounds, but not eight and ten sounds.

The present study conceptually followed the same procedures used in habituationdishabituation studies that test auditory perception in infants. The methodology of my study is similar in design to Lipton and Spelke (2003). In my study, test sessions consisted of ten trials of a rhythm (familiar rhythm), followed by six test trials that alternated between the familiar rhythm and a novel rhythm. After a fixed familiarization period, I used a post hoc habituation criterion similar to those used in many of the infant studies described above although I used a different response measure for the penguins (orienting responses were summed across groups of penguins, rather than individual penguin head turns). Many infant studies consider habituation criterion to be met if the average of the last three familiarization trials is less than half of the average of the first three familiarization trials (Lipton \& Spelke, 2003; Pickens \& Bahrick, 1995). Habituation criterion was met if the average of the last three familiarization trials was at least half of the average of the first three familiarization trials (e.g. Lipton \& Spelke, 2003; Pickens \& Bahrick, 1995).

Animal studies. Habituation-dishabituation methods have been used to study auditory stimulus discrimination in many non-human animal species. A similarity among most habituation-dishabituation studies with animals is that many of them use head turning as a dependent variable. I counted the total number of head turns of penguins in a group as the 
dependent variable in my study, so examining the methodology of other habituationdishabituation studies based on head turning is important. Ramus et al. (2000) used a habituation-dishabituation method to examine human infants' and cotton-top tamarins' discrimination between sentences in Dutch and in Japanese. The dependent variable for infants was pacifier sucking and the dependent variable for the tamarins was head turning. Results revealed that once infants and tamarins were habituated to a particular language, upon the presentation of the novel language, infants would increase pacifier-sucking, and tamarins would increase head turning. This dishabituation suggests both species perceived the novel language as different from the familiar language. There was no dishabituation when the languages were played backwards. Experimenters concluded that infants and tamarins were using prosodic cues, the stress and intonation patterns of each language, in their discrimination. Habituationdishabituation studies have also been used to learn if species can discriminate between different types of vocalizations from conspecifics.

Fischer (1998) used a habituation-dishabituation method to learn if free ranging macaques in a reserve could distinguish pre-recorded shrill barks from conspecifics in two distinct scenarios. "Nocturnal disturbance" calls were recorded when the macaques that were disturbed by an experimenter while they were sleeping. "Dog" calls were recorded from macaques that were exposed to a dog. Sessions composed of familiarization trials and test trials occurred opportunistically, when animals were separate from the group. In familiarization trials, either the "Dog" or the "Nocturnal disturbance" call, was played until the macaque showed no response, in the form of head turns, for three consecutive trials. Once this habituation criterion was met the test stimulus, composed of calls from the opposite scenario, was played. Control sessions, where the familiarization stimulus was repeated upon habituation criterion, also 
occurred. Looking time toward the speaker during the familiarization trials and test trial was quantified through video analysis. Looking time revealed significant dishabituation when acoustic parameters in the calls changed and when the calls were from a different scenario.

Svedson et al. (2012) found that minks (Neovison vison) could discriminate between high and low pitch tones using the habituation-dishabituation method. Minks were played either a 2 $\mathrm{kHz}$ or an $18 \mathrm{kHz}$ tone for ten seconds at a time with 60 second inter-trial intervals. They were played one tone for three trials and then on the fourth trial, they were played the opposite tone. Dishabituation was quantified by comparing responding in the first three trials to the fourth trial with the novel stimulus using an ethogram. The most frequently observed behavior in the ethogram when an auditory stimulus played was a head turn. Other reactive behaviors such as body turns, freeze responses, scratching, moving around actively and standing, sitting or lying in the cage without moving were seen as well. They found that minks exposed to the $2 \mathrm{kHz}$ tone first significantly dishabituated when presented with an $18 \mathrm{kHz}$ tone but the minks exposed to the $18 \mathrm{kHz}$ tone did not dishabituate significantly when exposed to the $2 \mathrm{kHz}$ tone.

In summary, habituation-dishabituation paradigms can be used to test discrimination of auditory stimuli in non-human animals. This method was used to see tamarins could discriminate between two languages (Ramus et al., 2000), if macaques discriminated communication signals from different scenarios (Fischer, 1989), and if minks could discriminate pitch (Svedson et al., 2012). In the current study, the habituation-dishabituation method will be used to learn if penguins can discriminate between different rhythms.

Group habituation. One unique element of my study is that I am attempting to use a habituation-dishabituation method to test auditory discrimination in a group of animals rather than with individuals. Although the habituation-dishabituation method has apparently not yet 
been used on a group of animals, there is evidence that habituation can be seen in groups of animals who have repeated exposure to stimuli. Groups of mountain goats were observed when helicopters flew overhead and their collective behavior was observed to determine if they the group habituated or not to the disturbance (Cote, Hamel, St-Louis, \& Mainguy, 2013). The herd's collective behavior was categorized as light/not disturbed (the animals continued their pre-helicopter activity), moderately disturbed (the animals moved 10-100 meters or were alert for 2-10 minutes), or strongly disturbed (the animals moved over 100 meters or were alert for over 10 minutes) if 50\% or more of the group reacted in a given way. Over the course of four years, mountain goats never completely habituated to the helicopters. Their behavior was never consistently light/non-disturbed in the presence of overhead helicopters.

A similar study was conducted to learn if king penguins would habituate to the presence of helicopters. Hughes et al. (2008) studied the effects of helicopters on a colony of king penguins (Aptenodytes patagonicus). They wanted to learn if over a long period of exposure to the helicopters, penguins would habituate to the disturbance. Experimenters flew a helicopter over the colony a total of seventeen times over eight days. To test if the animals habituated to the disturbance, experimenters video recorded penguins during the helicopter flights and categorized individual birds in the colony into one of three behavioral states: resting (sleeping or lying motionless), displacement (comfort behaviors), or active (vigilance behaviors; including head turning). The proportion of animals in a given behavioral state (out of 24 birds selected each time a helicopter flew over) was calculated. Over the eight days of the experiment, the proportion of non-incubating adult penguins in the active state decreased from $100 \%$ to $40 \%$ indicating that the penguins had somewhat habituated to the helicopter flights. Hughes et al. (2008) provides an example of what habituation of a large group of penguins looks like. This is 
important to my study, because I aimed to habituate a group of penguins to a rhythmic stimulus. I was unable to separate my animal subjects for test sessions due to the restrictions placed on the study by the Seneca Park Zoo. Hughes et al. (2008) listed the behaviors typically seen in disturbed penguins and calm penguins which helped me decide upon head turning as a dependent variable for my study.

Another study that provided me insight when deciding on an appropriate dependent variable for my study was conducted by Gene Fowler (1999) with Magellanic penguins in Argentina. Fowler (1999) exposed Magellanic penguin colonies that were not accustomed to human visitors, and penguin colonies from heavy tourist areas to a human experimenter. To cause disturbance, a human would stand 1 meter from a nest for five minutes. During the first minute of the five-minute period head turns referred to as "alternate stares" were counted. Each change of side of the penguin's head was counted. Vocalizations and general behavior of the animals were recorded throughout the entire five-minute period. Penguins from the tourist areas showed less alternate stares less when exposed to the human experimenter than penguins from the beach with minimal human exposure. This indicated that the penguins in colonies frequently by tourists had potentially habituated to human visitors in close proximity to their nests. This study confirmed that counting the number of head turns was an appropriate dependent variable for my study group. I also used the same counting method as Fowler (1999) as a model when counting the head turns of the penguins in my study. Fowler (1999) counted each rotation to the left or right as a single head turn, I did the same when coding videos of my test sessions.

\section{Sound Perception and Production in the African Penguin}

Sound perception. Wever, Herman, Simmons and Hertzler (1969) tested hearing in the African penguin in air by measuring evoked cochlear potentials (the only audiogram available 
for any penguin species). No underwater audiogram is available for any penguin species.

Experimenters measured cochlear potentials for frequencies of 100 to $15,000 \mathrm{~Hz}$ by successively increasing the sound pressure level of stimuli by $5 \mathrm{~dB}$ re $20 \mu \mathrm{Pa}$ until a potential of $0.1 \mu \mathrm{v}$ was evoked in the round window of the subjects' inner ears. They found that penguins can hear frequencies between $100 \mathrm{~Hz}$ to $10,000 \mathrm{~Hz}$, with optimal hearing of approximately $4 \mathrm{kHz}$ (Wever, Herman, Simmons, \& Hertzler, 1969). The audiogram of African penguins is similar in range and shape to that of other bird species. On average birds have the highest sensitivity to sounds between 2 and $5 \mathrm{kHz}$ with absolute thresholds close to $0 \mathrm{~dB}$ re $20 \mu \mathrm{Pa}$ in air and a loss of sensitivity below $1 \mathrm{kHz}$ and above $4 \mathrm{kHz}$ of (Dooling, Lohr \& Dent, 2000). Wever et al. (1969) is the only study to date to investigate hearing in penguins, however it is clear that penguins are able to receive vocal signals in environments with low signal to noise ratios (Aubin et al., 2004; Aubin \& Jouventin, 2002). Background noise (e.g., wing flapping, wind) in a large king penguin (Aptenodytes patagonicus) colony measured over four minutes was on average $74 \mathrm{~dB}$ re $20 \mu \mathrm{Pa}$ (Aubin \& Jouventin, 2002).

Most species of penguins are thought to use only auditory signals to locate their kin. Penguins accomplish this in large colonial breeding grounds where other birds are vocalizing at volumes up to $75 \mathrm{~dB}$, and thousands of penguin bodies are attenuating sound (Aubin 2004; Aubin \& Jouventin, 2002). Because of this ecological challenge, penguins have complex vocalizations that act as individual signatures for kin recognition. Penguins must decode these signatures despite the low signal to noise ratio they encounter in the colony. Rhythm potentially plays a role in individual recognition among penguins. Aubin (2004) revealed, through playback studies and statistical analyses of vocalizations, that many different in species of penguins, rhythmic characteristics (i.e. the duration syllables and number of syllables in a given period) 
and frequency modulations were unique to individuals and possibly held individual signatures. Through the playback studies Clark et al. (2006) learned that female Magellanic penguins (Spheniscus magellanicus) responded more strongly to the calls of their mates than to the calls of their neighbors. Penguin chicks also showed greater responding to their parents calls compared to calls of strangers.

Sound production. African penguins have a handful of stereotypical vocalizations that are similar from individual to individual; however, subtle differences within individual calls do exist. All penguin species have four types of calls: contact calls, agonistic calls, display calls, and chick produced calls (Aubin \& Jouventin, 2002; Favaro, Ozella, \& Pessani, 2014). King (Aptenodytes patagonicus) and emperor penguins (Aptenodytes forsteri; both non-nesting) incorporate two independent streams of sound into their vocalizations. In contrast, all remaining species of penguins (nesting) only produce a single vocal stream in their calls (Aubin \& Jouventin, 2002). Favaro et al. (2014) described the vocal repertoire of African penguins, categorizing into six basic types of calls: contact calls, agonistic calls, mutual display songs, ecstatic display songs, begging peeps (chicks only) and begging moans (chicks only). Calls can contain multiple syllables. Syllables in this case are defined as single units of sound within a sequence of sounds.

Contact calls are short $(\sim 0.58 \mathrm{~s})$, one syllable vocalizations that are repeated intermittently to communicate to the group, or their mate, when isolated from the crowd. Agonistic calls which are also short, and a single syllable $(\sim 0.44 \mathrm{~s})$, are emitted occasionally during fighting and territory defense. The mutual display song begins with a pulsed noise and ends with a clear low-pitched harmonic and lasts approximately $1.5 \mathrm{~s}$ and is emitted once. Mated pairs will engage in this vocalization simultaneously with one another. The ecstatic display song 
is the longest vocalization of the repertoire $(\sim 5 \mathrm{~s})$ and likely the most relevant to the current research because of the opportunity for it to vary in rhythm since it is composed of three syllable types: short syllables, long syllables, and an inhalation syllable.

Males and females emit ecstatic display songs to attract mates and advertise nest occupancy. Often when one penguin engages in an ecstatic display song, others in the colony will follow. This song is composed of about $12.3 \pm 1.3$ syllables. The standard song is composed of a series of short syllables (mean duration $=0.1860 \pm 0.05 \mathrm{~s}$ ) followed by two long syllables $($ mean duration $=1.14 \pm 0.33 \mathrm{~s})$ and a short inhalation syllable (mean duration $=0.38 \pm 0.12 \mathrm{~s})$ at the beginning of the next call. The final two calls described only apply to juvenile African penguins. These sounds were referred to as begging peeps $(\sim 0.36 \mathrm{~s})$ and begging moans $(\sim 0.27 \mathrm{~s})$ and are emitted continuously when chicks are calling for food. Contact calls and display songs seem to hold potentially useful information for individual recognition.

Favaro et al. (2015) recorded contact calls and ecstatic display songs from African penguins under human care and analyzed them based on spectral and acoustic parameters. For each parameter, they statistically assessed the ratio of within-individual variation and between individual variations in parameters. For vocalization parameters where within-individual variation was high, a statistical model artificially matched vocalizations to particular penguins. In contact calls, duration was a temporal parameter the model successfully used to assign vocalizations to individual penguins. Analyses of ecstatic display songs revealed temporal patterning of this call varies significantly between individuals. The features that varied significantly between individuals were the number and duration of all three distinct syllable types produced in the ecstatic display call. These differences were so robust they were visually detectable on the spectrograms. The statistical model was able to correctly assign $71.9 \%$ of the 
calls to individual penguins using the parameters with high within-individual and betweenindividual variation ratios. Further analysis revealed three rhythmic parameters that were the most important in assigning a vocalization to the correct penguin: the number and mean duration of the second syllable type, and the relative contribution of each syllable type to the total duration of the call. This shows that elements of the temporal structure (or rhythm) of the calls contain information distinct to individuals. The between-individual variation in temporal parameters seems to be characteristic across other Spheniscus penguins such as Magellanic penguins (Spheniscus Magellanicus), Humboldt penguins (Spheniscus humboldti) and African penguins (Speniscus demersus; Thumser \& Ficken, 1998).

Thumser and Ficken (1998) analyzed the calls of captive Humboldt (Spheniscus humboldti), African (Spheniscus demersus) and Magellanic penguins (Spheniscus magellanicus), by statistically pinpointing a handful of frequency and temporal components in vocalizations that were unique to individuals. Results of the study revealed that rhythmic components in the calls varied significantly between individuals such as duration, number of syllables, sum of intersyllable intervals and duration of the longest syllable. In African penguins, significant variation between individuals was seen in number of syllables, duration of the longest syllable and maximum frequency of the longest syllable. In summary, rhythmic characteristics of vocalizations vary between individuals. If detected, these temporal signatures could potentially aid penguins in recognition of individuals in large colonies where animals are difficult to discriminate visually.

\section{The Current Study}

Little is known about the perception of rhythm in all 18 species of penguins despite the fact rhythmic variations exist across call types and within individual animals' vocalizations 
(Thumser \& Ficken, 1998). The goal of this experiment is to investigate African penguins' ability to perceive rhythm using a habituation-dishabituation method. Although habituationdishabituation studies have not yet been conducted with groups of animals, habituation has been quantified for groups of penguins (Fowler, 1999; Hughes et al., 2008). In these studies experimenters record penguin's reactions to presumably disruptive stimuli in their environment (i.e. helicopters flying overhead or humans by their nests) over time and see if their behaviors return to baseline with repeated exposure.

In the current study, groups of 32-38 penguins at an indoor facility at the Seneca Park Zoo in Rochester, New York were tested. They were exposed to four different rhythmic stimuli: a stimulus with equal length tone and inter-tone intervals (known as an "isochronous" rhythm in Hattori et al., 2013; Large \& Gray, 2015; Merchant \& Hoening, 2014; Selezneva et al., 2013), a stimulus with equal length tone durations but varied inter-tone intervals, a stimulus with equal length inter-tone intervals but varied tone durations (this stimulus called "charge" was taken from D'Amato \& Salmon, 1982), and a stimulus where both tone and inter-tone intervals varied in length. Stimuli were all played at a frequency of $4 \mathrm{kHz}$ because African penguins are most sensitive to sounds played at $4 \mathrm{kHz}$ in air (Wever et al., 1969). Stimuli were also presented at a tempo of approximately five beats per second. This rate is similar to the vocalization rate of African penguin chicks when peeping ( $\sim 3.0$ tones per second, excluding inter-tone intervals; Favaro et al., 2014).

Each of the 24 test sessions was composed of 16 trials. Each trial consisted of $10 \mathrm{~s}$ of a rhythmic stimulus, and $30 \mathrm{~s}$ of silence. A stimulus deemed the "familiar" stimulus for that session was played for the first 10 trials to allow birds to habituate to that stimulus. The initial ten familiarization trials were followed by six test trials; three in which the familiar stimulus was 
played, and three in which a novel stimulus (that the penguins had not yet heard that day) was played. The six test trials alternated between the novel and familiar stimuli. The dependent variable was the number of head turns observed in animals that were visible across the entire test session in the video recordings (as in Fowler, 1999; Hughes et al., 2008; Ramus et al., 2000). Rhythm could play an important role in African penguin communication of individual identity (Favaro et al., 2015; Thumser \& Ficken, 1998). Rhythm is also an ideal medium for information in a loud noisy penguin colony (Aubin et al., 2000; Aubin et al, 2002; Aubin 2004). For these reasons, I hypothesized that the penguins would perceive differences in rhythmic stimuli. I expected to see evidence of this through a significant increase in head turns on the first novel test trial compared to the last three familiarization trials. I also expected to see significantly more head turns for novel rhythm test trials compared to familiar rhythm test trials.

\section{Ethical Considerations}

The work on animals was done according to the principles and guidelines of the Rochester Institute of Technology and the Seneca Park Zoo Institutional Animal Care and Use Committees (IACUC), and The United States' Guide for the Care and Use of Laboratory Animals regulations for the treatment of experimental animals. Approval from the Seneca Park Zoo IACUC and from the RIT IACUC were obtained before beginning the study.

\section{Method}

\section{Animal Subjects}

The subjects were African penguins housed at the Seneca Park Zoo in Rochester, New York. Throughout the duration of the study there were between 32 (16 adult males, 2 juvenile males, 13 adult females, 1 juvenile female) and 38 (16 adult males, 2 juvenile males, 11 adult females, 1 juvenile female, 8 unsexed chicks) healthy African Penguins (Spheniscus demersus) 
present. Table 1 provides subject information. Subjects included chicks (under three months), juveniles (under one year), and adults (1-23 years). All penguins were born under human care. Subjects were housed in an enclosure composed of two areas. The outdoor habitat on display to the public had a 56,781 L pool, a beach made of a cement and sand mixture, and tunnels for hiding. The indoor habitat off display from the public had a $1.2 \times 1.2 \times 1.2 \mathrm{~m}$ pool, 10 to 13 dens (varied from day to day), and multiple enrichment devices (e.g., colorful plastic chains hanging from the ceiling, dog toys, rocks stacked in various locations, plastic baby toys). All research sessions with the penguins occurred in the indoor habitat. The dimensions of the indoor habitat are shown in Figure 1.

All subjects were experimentally naïve at the time of the study and the animals' diets were not constrained for experimental purposes. Most penguins were fed twice daily, once between 9:00 am and 10:45 am and once between 2:00 pm and 4:00 pm. Nesting penguins with chicks were fed approximately five times throughout the day. Feeding times varied daily based on the keeper's schedules. Subjects' diets consisted entirely of fish supplemented with vitamins. Penguins were fed silversides (Menidia menidia), rainbow trout (Oncorhynchus mykiss), and capelin (Mallotus villosus). The penguins ate a minimum of four fish a day, and were fed until satiated.

\section{Materials}

Apparatus. An in-air speaker (FUGOOC Tough) was used to play auditory stimuli. The in-air speaker is shown in Figure 2. The speaker has a frequency response of $60 \mathrm{~Hz}$ to $20 \mathrm{kHz}$. The speaker also has a battery life of 40 hours and Bluetooth connectivity of up to $10.05 \mathrm{~m}$. The speaker was mounted in the penguin habitat out of reach of the animals, as shown in Figure 1. 
An Apple iPhone 6 was used to play mp3 stimuli. The experimenter played stimuli on the speaker remotely from the iPhone via Bluetooth connection.

Two Go-Pro@ cameras (Hero3+ and Hero 4) were mounted using adhesive 3M brackets (for positioning of cameras see Figure 1). These cameras were used to capture video footage of all pilot and test sessions. Cameras were positioned above the penguins at opposite ends of the room to capture the entire indoor portion of the penguin habitat. This ensured that all animals that were not in their dens could be seen on camera (for camera points of view see Figure 3). The experimenter was out of sight of the penguins during stimulus presentation and watched penguin behavior through two small windows located in the diet preparation area of the penguin building.

Stimuli. Auditory stimuli were generated using Audacity ${ }^{\circledR}$ 2.1.2 (2016). All stimuli were created using a pure $4 \mathrm{kHz}$ tone and periods of silence. The frequency of stimuli was selected because African penguins are most sensitive to sounds played at $4 \mathrm{kHz}$ in air (Wever et al., 1969). Stimuli were presented at a tempo of approximately five beats per second (or 2.5 tones per second, excluding inter-tone intervals) which is similar to the vocalization rate of African penguin chicks when peeping ( $\sim 3.0$ tones per second, excluding inter-tone intervals; Favaro et al., 2014). Stimuli were played at a sound pressure level of $70 \mathrm{~dB}$ re $20 \mu \mathrm{Pa}$. A battery powered sound level meter (Tacklife SLM01 Classic Decibel Meter) was used to verify that stimuli were played at a constant sound pressure level at the beginning of each session. The experimenter took $\mathrm{dB}$ readings from three fixed locations in the penguin habitat: a central location $(1.22 \mathrm{~m}$ back and $0.41 \mathrm{~m}$ to the right of the speaker), and from the position of each of the two cameras. The three positions where sound pressure level readings were taken are indicated by black stars in Figure 1. 
In the central location, the sound pressure level was always set to $70 \mathrm{~dB}$ re $20 \mu \mathrm{Pa}$.

Measurements from the camera locations were always within $2 \mathrm{~dB}$ of $70 \mathrm{~dB}$ re $20 \mu \mathrm{Pa}$.

Figure 4 shows the stimuli used in the study. One of the sounds presented to subjects was isochronous, meaning all tones and intervals were the same duration. The isochronous stimulus consisted of alternating tones and inter-tone intervals of $250 \mathrm{~ms}$. The "Hierarchical" stimulus is adapted from Hulse et al. (1984), and tone lengths are equal to those in the isochronous stimulus, but inter-tone intervals are different. This is to control for the possibility that only tone length, and not rhythm, is controlling the penguins' behavior. Another stimulus, "Charge”, was adapted from a stimulus used in D'Amato and Salmon (1982). This stimulus was selected because it has tones that vary in duration from the isochronous stimulus and from one another, but the duration of inter-tone intervals is constant throughout the Charge stimulus. This stimulus was used to control for the possibility that only inter-tone length, and not rhythm, could be controlling the penguins' behavior. The "Long/short" stimulus is original and varies from the isochronous stimulus in both tone and inter-tone interval duration.

\section{Procedure}

Pilot study. The pilot study occurred between November 2016 and January 2017. The main goals of the pilot study were to develop an ethogram of the penguins' baseline behavior, observe how the animals responded to auditory stimuli, and to determine how long it would take for penguins to habituate to auditory stimuli. The pilot study was composed of three stages.

Stage 1.a. In Stage 1, penguins were observed in their indoor habitat without being presented with auditory stimuli. The purpose of this stage was to habituate birds to equipment, develop an ethogram, and observe baseline behavior. The goal of Stage 1.a. of the pilot study was to set up equipment (cameras) and observe and record penguin behavior in same the location 
and at the same time test sessions would eventually occur. During this stage, cameras were positioned and captured footage of the penguins for an hour. The experimenter stayed in the fish preparation area and observed the animals from small windows. The experimenter recorded the animals observed in the given session and notable behaviors to help with animal identification during the session. Later, the experimenter watched the footage and compiled a comprehensive list of animal behaviors and developed an ethogram. The most frequent behaviors observed are shown in Table 2.

Stage 1.b. Once Stage 1.a. was complete and an ethogram was developed, Stage 1.b. began. The goal of this stage was to observe the penguins and fill out an ethogram to establish baseline behavior. During this stage, one hour of film was recorded from each camera. The speaker was not mounted during this stage. During the session, the experimenter recorded which penguins were present, their behaviors, and the times they occurred in relation to the start of the sessions as landmarks when coding film. Later, when coding the video sessions, an ethogram was used to record the behavior of a focal animals every $30 \mathrm{~s}$ in each video. Once the results of the ethogram revealed penguin behavior was similar from session to session (e.g., across sessions focal birds spent most of their time maintaining their feathers or standing, and very little time turning their heads; see Figure 5), the speaker was introduced in Stage 1.c.

Stage 1.c. The goal of Stage 1.c. was to habituate the penguins to the presence of the speaker (with no sounds playing). This stage was mostly identical to Stage 1.b., but the speaker was introduced and remained in the penguin habitat for the duration of the session. The cameras and the speaker were placed in the enclosure and then video was recorded for one hour. During the session, the experimenter recorded the penguins present during the session, as well as notable behaviors and the time they occur. An ethogram was used to code the footage collected during 
sessions. This stage continued for four sessions. The penguins' behavior did not change noticeably when the speaker was introduced. The penguins continued to spend most of their time standing and relatively little time turning their heads see Figure 5. Stage 1.c. was composed of six sessions, three before the introduction of the speaker and three after (see Table 3).

Stage 2. The goals of Stage 2 were to establish an orienting response to auditory stimuli and learn how long it would take penguins to habituate to the carefully selected auditory stimuli that were unlike those to be played in data collection. Four pilot sounds were played in Stage 2: a female voice reading the alphabet, penguins from the Seneca Park Zoo vocalizing, wind chimes, and wild African penguin chicks vocalizing. The experimenter played up to three sounds in a session. In each session, each sound was played 5 or 10 times at $70 \mathrm{~dB}$ re $20 \mu \mathrm{Pa}$ for ten seconds, with either 30 second or 60 second intervals of silence in between stimuli presentations (see Table 4). Video footage from this stage was coded by counting the number of animals turning their heads and the number of animals engaged in other behaviors during the presentation of the pilot stimuli. Stage 2 pilot sessions revealed that head turning was an appropriate orienting response since penguins engage in head turning during the presentation of auditory stimuli. During this stage, which lasted a total of four sessions, the experimenter was also able to observe habituation to the recordings of a female voice speaking the alphabet and Seneca Park Zoo penguin vocalizations. African penguin chick peeps and wind chimes were also played, but habituation was not observed to these stimuli (see Figure 6).

Stage 3. The goal of Stage 3 was to determine if penguins would respond to test stimuli as they did to pilot stimuli with head turns as an orienting response. Each test stimulus was played in at least one session. Sounds were played for for $10 \mathrm{~s}$ with $30 \mathrm{~s}$ inter-tone intervals at 70 $\mathrm{dB}$ re $20 \mu \mathrm{Pa}$ (see Table 4). During this stage, which lasted a total of three sessions, head turning 
was observed during the presentation of each test stimulus. Penguins showed habituation for two test stimuli (Isochronous and Long-short). They did not seem to show habituation for the Hierarchical stimulus over the course of ten trials, and it was difficult to know if they habituated to the Charge stimulus, as it was only played three times (see Figure 7).

Test sessions. Data collection consisted of 24 test sessions conducted from January $31^{\text {st }}$ to April $8^{\text {th }}, 2017$. The composition of all test sessions is shown in Table 5. Each of the four rhythms was used as a familiarization stimulus in six sessions. Each rhythm was paired with every other rhythm (e.g., Charge and Hierarchical, Charge and Isochronous, Charge and LongShort). Each combination was used in a "familiar first" and "novel first" condition to control for order effects. All experimental sessions occurred between 11:30 am and 1:00 pm, 30 minutes to two and a half hours after the penguins' morning feeding. Penguins participated in a single experimental session per day and were not reinforced with food during sessions. Sessions were conducted on Tuesdays, Thursdays, and Saturdays.

The procedure for each test session included equipment set-up, a waiting period, and sixteen trials. First, the experimenter entered the penguin habitat and mounted the two cameras and speaker (refer to Figure 1). After equipment was set up and dB meter readings were taken, the experimenter waited 25 minutes before beginning a test session to allow the penguins' behavior to return to baseline. Each session began with a habituation period where a test stimulus, deemed the "familiar" stimulus for that session, was played ten times for $10 \mathrm{~s}$ with $30 \mathrm{~s}$ inter-trial intervals (silence). Following the habituation period, six test trials occurred; three in which the familiar stimulus was played, and three in which a "novel" stimulus, one that the penguins had not yet heard that day, was played. The six test trials alternated between the novel and familiar stimulus. 
Video coding. For each session, the experimenter counted the number of head turns displayed by penguins when sounds were being played. This coding was always done blindly. During coding, videos were muted, so coders did not know which stimuli were playing. When Spheniscus penguins and other species of penguins are alert and vigilant, they swivel their heads back and forth to observe their surrounding with one eye, then the next (Eggleton \& Sigfried, 1979). Head turns were counted using the same method as Fowler (1999). Each change of the side of a penguin's head was counted as one head turn. Head turns were only counted for animals visible to cameras over the course of the entire session ( $\mathrm{n}=4-11$ birds $)$. Before coding, all videos were prepared for coding using iMovie (version 10.1.5). The experimenter time-stamped the points in the video when stimuli were presented in the video, and indicated when to begin and stop counting head turns. All sessions were recorded and scored by the experimenter using consistent criteria (see Appendix).

Inter-rater reliability. A second coder coded videos to check for inter-rater reliability to control for potential experimenter bias. The second coder coded eight of the twenty-four sessions (about $30 \%$ of data). The second coder had no prior experience coding behavioral videos or observing penguins and did not know what predictions were being tested. The second coder attended two training sessions with the experimenter. In the first training session, the experimenter slowly coded a session and explained head turning criteria while the second coder observed. In the second training session, the second coder coded a session slowly, taking time to ask questions from the experimenter, who was observing the second coder closely. The second coder was paid $\$ 10 /$ hour and spent 15 hours coding 8 sessions.

Agreement in the inter-rater reliability check was calculated by dividing the larger total number of head turns in a session for all birds combined (counted either by the first or second 
coder) by the smaller counted number of head turns (see Table 6). Results for of the inter-rater reliability check revealed $87 \%$ agreement over all sessions, and individual sessions had an agreement rate which ranged from $80-98 \%$ across seven sessions. An eighth session initially had a low agreement value of $52 \%$. The experimenter recoded this session and found that the disagreement came from an error made by the second coder. The second coder coded a different penguin than the experimenter in attempt to code a penguin referred to as "Unknown Penguin 1". The experimenter recoded the entire session counting head turns for the same "Unknown Penguin 1" as the second coder, which resulted in a 98.94\% agreement rate. This eighth session was excluded due to the error made by the second coder.

\section{Results}

For every session, including all familiarization trials and test trials, the total number of head turns for all birds per trial was divided by the total number of birds present across the entire session because the number of birds visible throughout the entire session varied from session to session $(\mathrm{n}=4-11)$. This calculation resulted in a value I will refer to as "head turns per bird" (as in Fowler, 1999). Table 7 shows the number of birds present in each test session. Descriptive statistics were calculated for the average head turns per bird across the final three familiarization trials (trials 8, 9 and 10) and the first novel test trial (trials 11-16; see Table 8), all novel and familiar test trials (see Table 9) and for the average of all novel tests and all familiar tests (see Table 10).

The results are divided into three sections: (1) analyses for the ten familiarization trials, (2) a comparison between the last three familiarization trials and first novel test trial (where dishabituation could occur), and (3) analyses of the six test trials in which the stimulus being played alternated between the novel rhythm and the familiar rhythm. 


\section{Familiarization Trials}

A habituation criterion similar to those used in previous studies was used to define habituation (Beier \& Spelke, 2012; de Hevia \& Spelke, 2010; Pickens \& Bahrick, 2011). To meet habituation criterion, the mean total head turns counted in the last three familiarization trials $(8,9$ and 10$)$ in a session had to be at most $50 \%$ of the mean total head turns in the first three familiarization trials (trials 1, 2 and 3). In 9 out of the 24 test sessions, penguins habituated to the familiar stimulus. Penguins did not meet this habituation criterion in 15 sessions (see Table 7).

Unfortunately, there was not an equal number of sessions in which the habituation criterion was met for each of the familiarization rhythms. Interestingly, penguins did meet the habituation criterion in five out of the six sessions where the Isochronous rhythm was the familiarization rhythm. In contrast, penguins never met habituation criterion in sessions where the familiarization rhythm was Charge and only met habituation criterion in two out of six sessions where the familiarization rhythm was Hierarchical or Long-short.

Another interesting observed pattern was that the average number of birds observed was slightly lower in sessions where birds habituated to the familiar stimuli $(M=5.78 \pm 1.40)$ than when they $\operatorname{did} \operatorname{not}(M=7.10 \pm 2.22)$. There were also fewer sessions meeting the habituation criterion in the final 12 test sessions ( 3 sessions) compared to the first 12 test sessions (6 sessions). The penguins met the habituation criterion more often during the first half of the experiment and when there were fewer birds present. 


\section{Transition from Familiarization Trials to First Novel Test Trials}

I compared the end of the familiarization trials (last three trials) to the first novel test trial using a repeated measure analysis of variance (ANOVA) to investigate whether the head turning behavior of penguins changed when the first novel rhythm was played in the test trials (see Figure 8a). All $p$-values were adjusted using Holm's method for multiple comparisons (Holm, 1979). A 2 (habituation condition: habituation criteria met, habituation criteria not met) x 2 (trial type: average of last three habituation trials, first novel test trial) x 4 (familiarized rhythm: Charge, Hierarchical, Isochronous and Long-short) ANOVA was conducted on number of head turns per birds across all sessions $(\mathrm{N}=24)$.

Contrary to expectations, the ANOVA revealed no statistically significant main effect of trial type, $F(1,42)=5.00, p>0.05$. The average number of head turns per bird for the final three familiarization trials $(M=0.90,95 \% C I=0.72,1.09)$ was not significantly different than the average number of head turns per bird for the first novel test trial $(M=1.18,95 \% C I=1.00$, 1.37). The penguins did not turn their heads more when presented with a novel rhythm after hearing a familiar rhythm for ten trials (see Figure 8a).

The ANOVA also revealed no significant main effect for habituation condition, $F(1,42)$ $<1, p>0.05$. The average number of head turns per bird not significantly different in sessions where the habituation criteria was met $(M=1.06,95 \% C I=0.82,1.31)$ than when it was not met $(M=1.03,95 \% C I=0.85,1.65)$. Penguins in sessions considered to be habituated to the familiar rhythm did not turn their heads more often upon first presentation of the novel rhythm compared to sessions where they did not habituate (see Figure $8 \mathrm{~b}$ and Figure 8c).

Finally, the ANOVA showed no significant main effect for familiarization rhythm, $F(3$, $42)=2.22, p>0.05$. There were no significant differences in average number of head turns per 
bird among sessions beginning with each of the four familiarization rhythms: Charge: $M=1.18$, $95 \% C I=0.70,1.66$; Hierarchical: $M=0.85,95 \% C I=0.43,1.26$; Isochronous: $M=0.91,95 \%$ $C I=0.47,1.36$; Long-Short: $M=1.24,95 \% C I=0.82,1.65$. The nature of the familiarization rhythm did not impact the number of head turns per bird in the first novel test trial. Head turns per bird in the first novel test trial was about the same for each of the four familiarization rhythms (see Figures 9-13).

\section{Test Trials}

A second repeated measures ANOVA was used to analyze average head turns per bird across the six test trials. Again, all $p$-values were adjusted using Holm's method for multiple comparisons. A 2 (habituation condition: habituation criteria met, habituation criteria not met) $\mathrm{x}$ 3 (test trial order: first pair, second pair, third pair) x 4 (familiarization rhythm: Charge, Hierarchical, Isochronous and Long-short) x 2 (trial type: Novel vs. Familiar) ANOVA was conducted on head turns per birds across the three sets of test trials.

Contrary to my hypothesis, there was no main effect of trial type, $F(1,136)<1, p>0.05$. The penguins did not turn their heads more often on novel trials compared to familiar trials (see Table 11 and Figure 8a). There was also no significant main effect of test trial order, $F(2,136)<$ $1, p>0.05$. The penguins did not change their head turning behavior throughout the test trials (see Table 11 and Figure 8a). The results of the ANOVA also revealed no significant main effect for habituation, $F(1,136)=1.03, p>0.05$. Meeting habituation criteria (or not) during the familiarization trials did not change their head turning behavior throughout the test trials (see Table 11 and Figure 8b and 8c). Finally, the ANOVA showed no significant main effect for familiarization rhythm, $F(3,136)<1, p>0.05$. The identity of the familiarization rhythm did not impact head turning in the test trials (see Table 11 and Figures 9-13). 


\section{Discussion}

This is the first behavioral study to explore rhythm discrimination in captive African penguins. Other studies have found rhythmic properties such as duration of certain syllables and total duration of inter-tone intervals in wild and captive penguin calls (Favaro et al. (2015) and Thumser \& Ficken (1996) in Spheniscus species and Aubin et al. (2000) in Aptenodytes species). The previous studies however, all relied on analysis of recorded vocalizations for intra-individual differences in rhythms of calls. In the current study, penguins were presented with multiple rhythmic sequences (of the same frequency and loudness) in a habituation-dishabituation paradigm.

The results of the current study did not provide evidence that African penguins perceive changes in rhythm. The penguins did not turn their heads more often when a novel rhythm was played after hearing a familiar rhythm during the ten familiarization trials. Over all test sessions, head turns per bird did not significantly increase from the last three familiarization trials (where penguins were hearing a familiar rhythm) to the first novel test trial (where penguins were played a rhythm that was novel in that session). There was also no significant difference in head turns per bird in the three novel rhythm test trials vs. the three familiar rhythm test trials.

The first conclusion one could draw from the results of the current study is that African penguins are unable to discriminate differences in auditory rhythms. Perhaps rhythm perception is not important to penguins. It could be that rhythms exist in penguin vocalizations, but other acoustic parameters such as frequency or amplitude are more important to penguins in 
interpreting vocalizations. An alternative explanation for the results of the current study is that the limitations of the experimental design were not ideal for discovering rhythm perception in penguins.

Second of all, perhaps a habituation-dishabituation paradigm was not an appropriate method to use for the study of rhythm perception in African penguins. Typically, habituationdishabituation studies are carried out in a closely controlled environment where the subject is only exposed to the focal stimulus. In the current study, we were unable to eliminated distracting stimuli (whether they be auditory, visual or other modalities) due to the constraints placed on the research by the Seneca Park Zoo. If the penguins were trained on a discrimination task, or to entrain motor movements to an underlying beat, perhaps I would have found different results. However, training tasks involve extensive time and resources that were unavailable in the current study.

Another possibility is that the habituation-dishabituation methodology used in the current study had too many limitations and constraints to reveal significant evidence of rhythm perception in African penguins. First, due to time restrictions, there were only 24 test sessions, with only six test sessions collected for each of the four possible familiarization rhythms. There was inadequate statistical power to find differences in penguins' behavior in response to the four possible familiarization rhythms. In future studies, more test data should be collected for each rhythm pairings if investigators want to know whether penguins discriminate between particular rhythmic sequences but do not perceive differences between other sequences. I could have also included an arrhythmic stimulus to investigate whether penguins could discriminate rhythmic sounds from arrhythmic sounds (as in Aa et al., 2015; Hagmann \& Cook, 2010; Hulse et al., 1984). This would tell me if penguins have any sensitivity to temporal patterning in general. 
Another limitation of this research was that I only used four different types of rhythms in my test sessions. There were potentially many possible rhythmic test stimuli. I selected stimuli in a systematic way. I used stimuli where tone and inter-tone interval duration were identical across the rhythm (Isochronous), where only tone duration was consistent within the rhythm (Hierarchical), where only inter-tone interval duration was consistent within the rhythm (Charge) and where both tone and inter-tone interval durations varied within the rhythm. It would be interesting to attempt this study with a new set of stimuli with rhythms that are more similar or more different from one another than the stimuli used in the present study. For example, I could have designed rhythms to match the rhythm of penguin's various vocalizations which would increase the ecological validity of the study. I could have also created a range of rhythms ranging from very similar to extremely different in relation to a simple rhythmic stimulus such as an isochronous rhythm. In the not-so-different category rhythms could vary from isochronous in the duration of a single unit (either tone or inter-tone interval), in the extremely different category, every tone and inter-tone interval unit of the rhythm would be different from the isochronous rhythm. These stimuli would allow me to titrate how different temporal patterns need to be from one another for penguins to perceive differences in rhythm.

An additional limitation of this study was that penguins only met habituation criterion in 9 out of 24 test trials. Interestingly, penguins seemed to reach habituation criterion most when Isochronous was the familiarization stimulus. This could be because penguins have a history of hearing Isochronous rhythms outside of the current study. For example, zoo keepers at the Seneca Park Zoo mentioned trucks that the zoo keepers use to transport heavy equipment make an isochronous tone when they are driving in reverse. When construction is occurring, hammers hitting nails are usually emitting an isochronous rhythm as well. Another isochronous sound that 
the Seneca Park Zoo's penguins are regularly exposed to are African penguin chick begging peeps (Favaro et al., 2014). The zoo has a very successful breeding program, so the penguins are exposed to begging peeps consistently throughout the year. It is possible that the remaining rhythmic stimuli (Charge, Hierarchical and Long-short) were too foreign for penguins to habituate to in only ten trials. Perhaps if I designed all of my rhythmic stimuli to mimic the rhythmic structure of penguin vocalizations, I would have seen habituation in fewer trials like I saw for the isochronous stimulus.

There was no statistically significant difference in head turns per bird in trials where penguin did and did not meet habituation criterion, however it would have been ideal if penguins met habituation criterion in all sessions. This could have been because the set ten trial familiarization period did not give penguins adequate exposure to the familiar stimulus to meet habituation criterion. Perhaps in future studies, familiarization trials should continue until the habituation criterion is met and if criterion is not ever met, the session should be eliminated from analyses. Another potential solution to this would be to test individual birds in isolation as habituation seemed to be disrupted by animal interactions (e.g., if two penguins got in fight on the tenth trial of the familiar stimulus and all the other penguins react by turning their heads).

Isolating birds would also mitigate the limitation that birds in the present study were tested in a large group. Habituation-dishabituation methods with human infants and non-human animals are typically conducted on one subject at a time (Fischer, 1988; Lipton \& Spelke, 2003; Svedson et al., 2012). It is possible that the penguins head turning behavior was influenced by auditory stimuli being played in test sessions as well as social interactions between birds. For example, if one bird pecked another bird and emitted an agonistic call, it could produce head turning of other birds. Penguins also could have responded with head turning to chicks peeping 
during test sessions. However, previous studies have observed habituation in groups of penguins through analysis of behavioral response to prolonged exposure to stimuli (Fowler, 1999; Hughes et al., 2008). The zoo did not permit the separation of subjects during test trials. Testing penguins in groups, however, may have increased the ecological validity of my study as penguins are always found in social groups and synchronize behaviors such as diving and feeding with those of other animals (Siegfried et al., 1975).

A final limitation of this study is that I repeatedly tested the same penguins 24 times. This was because I had to test the penguins in groups, and I only had one group of animals to work with. In the habituation-dishabituation studies with human infants, participants are never tested more than once (e.g., Beier \& Spelke, 2012; de Hevia \& Spelke, 2010; Pickens \& Bahrick, 2011). It would be interesting to see if I would find behavioral evidence for rhythm perception in penguins if each penguin was isolated in test sessions and only tested once to prevent a dampened response with repeated exposure. However, penguins are not typically isolated from their colony (Siegfried et al., 1975). Forced isolation could cause stress that might affect results.

Despite the findings of my study, there are still many reasons to expect that African penguins should be able to perceive changes in rhythm. Analyses of African penguin ecstatic display songs have found intra-individual differences in duration of the longest syllable (Thumser \& Ficken,1996), and the number and mean duration of the second syllables type and the relative contribution of each of the three-syllable type to the total of the song (Favaro et al., 2015). It is possible that African penguins are using rhythmic cues to identify their kin based on their songs. The perception of rhythm, in theory, would an adaptive perceptual ability for African penguins because their vocalizations are rhythmic in nature (Favaro et al., 2014). 
It made the most sense to study auditory rhythm perception in penguins since rhythms occur in their vocalizations. However, rhythm can be perceived through other sensory modalities such as vision. For example, bushbabies (Galago senegalensis) and rabbits (Oryctolagus cuniculus) have been shown to discriminate temporal patterns presented acoustically or visually (Ward, Yehle, \& Doerflein, 1970; Yehle \& Ward, 1969). It would be interesting to learn if penguins are also sensitive to visual or tactile rhythmic stimuli. If rhythm perception is in fact due to oscillating neurons in the brain, this implies the ability to perceive rhythms across many sensory modalities as any repeated stimulus could set off synchronous firing of neurons in the brain (Large, 2008). Studying rhythm perception in a variety of sensory modalities, across many animal species, could strengthen evidence for the neural oscillation theory.

In the future, I would like to see the habituation-dishabituation paradigm used to study rhythm perception across many other non-human animal species. Because the habituationdishabituation method capitalizes on naturally occurring behavior, it could be easily modified to study rhythm perception a wide range of species. Caution should be used to ensure that the habituation-dishabituation method is carried out in an appropriate environment and on individual subjects rather than in a group setting. For example, if I wanted to study the perception of rhythm in the domestic cat (Felis catus), another non-vocal learning animal, I could use the design of the current study with minor adjustments such as changing the frequency of stimuli to $8 \mathrm{kHz}$ (the frequency which they are most sensitive; Heffner \& Heffner, 1985) and modifying the tempo to match the average rate of the domestic cat's vocalizations. If the habituation-dishabituation method becomes a widespread test for rhythm perception in animals, it could reveal if rhythm perception is a common cognitive ability in non-human animals or if it is limited to vocallearning non-human animals. 


\section{Conclusion}

This study was the first to explore auditory rhythm perception in penguins using a habituation-dishabituation paradigm. Analyses of African penguin ecstatic display songs suggest that there are rhythmic properties in penguin vocalizations (Favaro et al., 2015, Thumser \& Ficken, 1996). Inter-individual differences in the rhythms of African penguin vocalizations may play a part in auditory kin recognition (Favaro et al., 2015). Additionally, penguin vocalizations that are used to communicate different scenarios have different rhythms and are emitted and interpreted by penguins regularly (Favaro et al., 2014). However, none of the previous studies aimed to learn if penguins perceived these differences in rhythm. The results of this study provided no evidence for rhythm perception in African penguins. One possible conclusion to draw from these results is that that penguins are unable to perceive differences in rhythms. Alternatively, one could conclude that the present study did not reveal rhythm perception in penguins because of the limitations and constraints of the chosen method. Based on what is known about penguin vocalizations and their ecological functions, it is likely that future studies may reveal that penguins can perceive rhythm. Because of the expanding body of research supporting rhythm perception throughout the animal kingdom, it is becoming more accepted as an adaptive, widespread perceptual ability. The benefits of rhythm perception seem to be important to animals in many elements of their lives. Rhythm perception allows for complex communication and synchronous behavior. Rhythm perception also enables animals to anticipate the timing of stimuli (whether they be auditory, visual or tactile) in their environments which ultimately increases species survival. 


\section{References}

Aa, J. V. D., Honing, H., \& ten Cate, C. (2015). The perception of regularity in an isochronous stimulus in zebra finches (Taeniopygia guttata) and humans. Behavioural Processes, 115, 37-45.

African penguin Spheniscus demersus. (n.d.). Retrieved from http://www.iucnredlist.org/ Apple Inc (2017). iMovie [Computer software]. Version 10.5.1. Cupertino, CA: Apple Inc.

Aubin, T. (2004). Penguins and their noisy world. Annals of the Brazilian Academy of Sciences, $76(2), 279-283$.

Aubin, T. \& Jouventin, P. (2002). How to vocally identify kin in a crowd: The penguin model. Advances in the Study of Behavior, 31, 243-277.

Aubin, T., Joventin, P., \& Hildebrand, C. (2000). Penguins use the two-voice system to recognize each other. Proceedings of the Royal Society B, 267, 1081-1087.

Audacity Team (2016). Audacity [Computer software]. Version 2.1.2. Retrieved from https://sourceforge.net/projects/audacity/

Bispham, J. (2006). Rhythm in music: What is it? Who has it? And why? Music Perception: An Interdisciplinary Journal, 24(2), 125-134.

Cook, P., Rouse, A., Wilson, M., \& Reichmuth, C. (2013). A California sea lion (Zalophus californianus) can keep the beat: Motor entrainment to rhythmic auditory stimuli in a non-vocal mimic. Journal of Comparative Psychology, 127(4), 412-427.

Cote, S. D., Hamel, S., St-Louis, A., \& Mainguy, J. (2013). Do mountain goats habituate to helicopter disturbance? Journal of Wildlife Management, 77(6), 1244-1248. 
Clark, J. A., Boersma, P. D., \& Olmsted, D. M. (2006). Name that tune: Call discrimination and individual recognition in Magellanic penguins. Animal Behaviour, 72, 1141-1148.

Craig, W. (1917). On the ability of animals to keep time with an external rhythm. Animal Behaviour, 7, 444-50.

Crawford, R. J., Barham, P. J., Underhill, L. G., Shannon, L. J., Coetzee, J. C., Dyer, B. M., ... Upfold, L. (2006). The influence of food availability on breeding success of African penguins Spheniscus demersus at Robben Island, South Africa. Biological Conservation, $132(1), 119-125$.

D’Amato, M. R., \& Salmon, D. P. (1982) Tune discrimination in monkeys (Cebus paella) and rats. Animal Learning and Behavior, 10(2), 126-134.

Demuth, K. (1996) The prosodic structure of early words. In J. Morgan \& K. Demuth (Eds.), Signal to Syntax: Bootstrapping from Speech to Grammar in Early Acquisition (pp. 171184). Mahwah, NJ: Lawrence Erlbaum Associates.

Dooling, R. J., Lohr, B., \& Dent, M. L. (2000). Hearing in birds and reptiles. In Comparative hearing: Birds and reptiles (pp. 308-359). Springer New York.

Doupe, A. J., Perkel, D. J., Reiner, A., \& Stern, E. A. (2005). Birdbrains could teach basal ganglia research a new song. Trends in Neurosciences, 28(7), 353-363.

Favaro, L., Gamba, M., Alfieri, C., Pessani D., \& McElligott, A. G. (2015). African penguin (Spheniscus demersus): A source-filter theory approach. Scientific Reports, 5, 1-12.

Favaro, L., Ozella, L. \& Pessani, D. (2014). The vocal repertoire of the African penguin (Spheniscus demersus): Structure and function of calls. PLOS ONE, 9(7), 1-10. 
Feenders, G., Liedvogle, M., Zapka, M., Horita, H., Hara, E., \&... Jarvis, E. D. (2008) Molecular mapping of movement-associated areas in the avian brain: A motor theory for vocal learning origin. PLOS ONE, 3(3), 1-27.

Fischer, J. (1998). Barbary macaques categorize shrill barks into two call types. Animal Behavior, 55, 799-807.

Fowler, G. S. (1999). Behavioral and hormonal response of Magellanic penguins (Spheniscus magellanicus) to tourism and nest site visitation. Biological Conservation, 90, 143-149.

Grafton, S. T., Hazeltine, E., \& Ivry, R. (1995). Functional mapping of sequence learning in normal humans. Journal of Cognitive Neuroscience, 7, 497-510.

Grahn, J., \& Brett, M. (2007). Rhythm and beat perception in motor areas of the brain. Journal of Cognitive Neuroscience, 19, 893-906.

Hagmann, C. A., \& Cook, R. G. (2010). Testing meter, rhythm, and tempo discriminations in pigeons. Behavioural Processes, 85, 99-10.

Hannon, E. E., Soley, G., \& Levine, R. S. (2011) Constraints on infants' musical rhythm perception of interval ratio complexity and enculturation. Developmental Science, 14(4), $865-872$.

Harley, H. E., Crowell, S., Fellner, W., Odell, K., \& Larsen-Plott, L. (2005). Rhythm perception and production by the bottlenose dolphin. Journal of the Acoustical Society of America, $118,1906$.

Harley, H. E., Fellner, W., Odell, K., \& Putnam, E. (2005). Representation of acoustic rhythms by the bottlenose dolphin. Presented at the 12th International Conference on Comparative Cognition, March 16-19, Melbourne, Florida. 
Harley, H. E., Odell, K., Fellner, W., Putnam, E., Clark, D., Goonen, C. (2003). Rhythm discrimination by the bottlenose dolphin. Presented at the 15th Biennial Conference on the Biology of Marine Mammals, December 14-19, Greensboro, NC.

Harley, H. E., Odell, K., Putnam, E., Goonen, C., \& DeLong, C. M. (2002). Belated ode to Stewart Hulse: Dolphins got rhythm. Presented at the 9th International Conference on Comparative Cognition, March 13-16, Melbourne, FL.

Harrington, D. L., Zimbelman, J. L., Hinton, S. C., and Rao, S. M. (2010). Neural modulation of temporal encoding, maintenance, and decision processes. Cerebral Cortex, 20, 12741285.

Hattori, Y., Tomonaga, M., \& Matsuzawa, T. (2013). Spontaneous synchronized tapping to an auditory rhythm in a chimpanzee. Scientific Reports, 3(1566), 1-6.

Heffner, R. S., \& Heffner, H. E. (1985). Hearing range of the domestic cat. Hearing Research, $19(1), 85-88$.

Hoeschele, M., Merchant, H., Kikuchi, Y., Hattori, Y., \& ten Cate, C.. (2015) Searching for the origins of musicality across species. Philosophical Transactions the Royal Society of Publishing, 370 .

Holm, S. (1979). A simple sequentially rejective multiple test procedure. Scandinavian Journal of Statistics, 6(2), 65-70.

Honing, H., ten Cate, C., Peretz, I., \& Trehub, S. E. (2015). Without it no music: cognition, biology and evolution of musicality. Philosophical Transactions of the Royal Society for Biotechnology Information, 370, 1-8.

Hulse, S. H., Humpal, J., \& Cynx, J. (1984). Processing of rhythmic sound structures by birds. Timing and Time Perception, 423, 407-419. 
Hulse, S. H., Takeuchi, A. H., \& Braaten, R.F. (1992). Perceptual invariances in the comparative psychology of music. Music Perception, 10(2), 151-184.

Kavsek, M., \& Bornstein, M. H. (2010). Visual habituation and dishabituation in preterm infants: A review and meta-analysis. Research in Developmental Disabilities, 31, 951-975.

Ksepka, D., Giannini, N. P., \& Bertelli, S. (2006). The phylogeny of the living and fossil Sphenisciformes (penguins). Cladistics, 22, 412-441.

Laiolo, P. (2010). The emerging significance of bioacoustics in animal species conservation. Biological Conservation, 143(7), 1635-1645.

Lakatos, P., Karmos, G., Mehta, A. D., Ulbert, I., \& Schroeder, C. E. (2008). Entrainment of neuronal oscillations as a mechanism of attentional selection. science, 320(5872), 110113.

Large, E. W. (2008). Resonating to musical rhythm: Theory and experiment. In S. Grondin (Ed.), The psychology of time (pp. 189-231). Cambridge, UK: Emerald.

Large, E. W., \& Gray, P. M. (2015). Spontaneous rhythmic entrainment in a Bonobo (Pan paniscus). Journal of Comparative Psychology, 129(4), 317-328.

Lipton, J. S., \& Spelke, E. S. (2003). Origins of number sense: Large-number discrimination in human infants. Psychological Science, 14(5), 396-401.

Maros, K., Pongracz, P., Bardos G., Molnar, C., Farago, T., \& Miklosi, A. (2008). Dogs can discriminate barks from different situations. Applied Animal Behavior Science, 114, 159167.

Melvin, E., Parrish, J.K., \& Conquest, L. L. (1999) Novel tools to reduce seabird bycatch in coastal gillnet fisheries. Conservation Biology, 13, 1386-1397.

Mercado, E., \& DeLong, C. M. (2010). Dolphin cognition: Representations and 
processes in memory and perception. International Journal of Comparative Psychology, 23(3), 344-378.

Merchant, H., \& Honing, H. (2014). Are non-human primates capable of rhythmic entrainment? Evidence for the gradual audiomotor evolution hypothesis. Frontiers in Neuroscience, 7(247), 1-14.

Merker, B., Madison, G. S., and Eckerdal, P. (2009). On the role and origin of isochrony in human rhythmic entrainment. Cortex 45, 4-17.

Morris, G. K., Kerr, G. E., and Fullard, J. H. (1978). Phonotactic preferences of female meadow katydids (Orthoptera: Tettigoniidae: Conocephalus nigropleurum). Canadian Journal of Zoology, 56, 1479-1487

Nazzi, T., Bertoncini, J., \& Mehler, J. (1998). Language discrimination by newborns: Toward an understanding of the role of rhythm. Journal of Experimental Psychology, 24(3), 756766.

Parsons, N. J., Schaefer, A. M., \& Vanstreels, R. E. (2016). Health evaluation of African penguins (Spheniscus demersus) in southern Africa: Original research. Onderstepoort Journal of Veterinary Research, 83(1), 1-13.

Patel, A. D., (2006). Musical rhythm, linguistic rhythm, and human evolution. Musical Rhythm and Evolution, 24(1), 99-104.

Patel, A. D., Iverson, J. R., Bregman, M. R., Schultz, I. (2009). Experimental evidence for synchronization to a musical beat by a nonhuman animal. Current Biology, 19, 827830. 
Phillips-Silver, J., Aktipis, C. A., \& Bryant, G. A. (2010). The ecology of entrainment:

Foundations of coordinated rhythmic movement. Music Perception: An Interdisciplinary Journal, 28(1), 3-14.

Pickens, J., \& Bahrick, L. E. (1995). Infants' discrimination of bimodal events on the basis of rhythm and tempo. British Journal of Development Psychological Society, 13, 223-236.

Ramus, F., Hauser, M. D., Miller, C., Morris, D., \& Mehler J. (2000). Language discrimination by human newborns and by cotton-top tamarin monkeys. Science, 288 , 349-351.

Reichmuth, C., \& Casey, C. (2014) Vocal learning in seals, sea lions, and walruses. Opinion in Neurobiology, 28, 66-71.

Rouse, A. A., Cook, P. F., Large, E. W., \& Reichmuth, C. (2016). Beat keeping in a sea lion as coupled oscillation: Implications for comparative understanding of human rhythm. Frontiers in Neuroscience, 10, 1-12.

Rouse, A., Cook, P., \& Reichmuth, C. (2015, December). A California sea lion shows human-like beat keeping in response to changing phase and tempo. Poster session presented at the 22nd Biennial Conference on the Biology of Marine Mammals, San Francisco, Ca.

Saar, S., \& Mitra, P. P. (2008), A Technique for characterizing the development of rhythms in bird song. PLOS ONE, 3(1). doi: 10.1371/ journal.pone.0001461

Saleh, M., Reimer, J., Penn, R., Ojakangas, C. L., \& Hatsopoulos, N. G. (2010). Fast and slow oscillations in human primary motor cortex predict oncoming behaviorally relevant cues. Neuron, 65(4), 461-471. 
Schachner, A., Brady, T. F., Pepperberg, I. M., \& Hauser, M. D. (2009), Spontaneous motor entrainment to music in multiple vocal mimicking species. Current Biology, 19, 831-836.

Selezneva, E., Deike, S., Knyazeva, S., Sceich, H., Brechmann, A., \& Brosch, M. (2013) Rhythm sensitivity in macaque monkeys. Frontiers in Systems Neuroscience, 7(49), 1-9.

Sherley, R. B., Underhill, L. G., Barham, B. J., Barham, P. J., Coetzee, J. C., Crawford, R. J., ... \& Upfold, L. (2013). Influence of local and regional prey availability on breeding performance of African penguins Spheniscus demersus. Marine Ecology Progress Series, $473,291-301$.

Siegfried, W. R., Frost, P. H. G., Kinahan, J. B., \& Cooper, J. (1975). Social behaviour of jackass penguins at sea. African Zoology, 10(1), 87-100.

Sumbre, G., Muto, A., Baier, H., \& Poo, M. M. (2008). Entrained rhythmic activities of neuronal ensembles as perceptual memory of time interval. Nature, 456(7218), 102-106.

Svedsen, P. M., Malmkvist, J., Halekoh, U., \& Mendl, M. (2012). Response of mink to auditory stimuli: Prerequisites for applying 'cognitive bias' approach. Behavioral Processes, 91, 291-297.

Thumser, N. N., \& Ficken, M. S. (1998). A comparison of the vocal repertoires of captive Spheniscus penguins. Marine Ornithology, 26, 41-48.

Trehub, S. E. (1987). Infants' perception of musical patterns. Perception \& Psychophysics, 41(6), 635-641.

Trehub, S. E., \& Thorpe, L. A. (1989) Infants' perception of rhythm: Categorization of auditory sequences by temporal structure. Canadian Journal of Psychology, 43(2), 217229. 
Wagner, W. E., \& Reiser, M. G. (2000). The importance of calling song and courtship song in female mate choice in the variable field cricket. Animal Behaviour, 59, 1219-1226.

Wiener, M., Turkeltaub, P., and Coslett, H. H. (2010). The image of time: A voxel-wise metaanalysis. Neuroimage, 49, 1728-1740.

Wever, E. G., Herman, P. N., Simmons, J. A., \& Hertzler, D. R. (1969). Hearing in the blackfooted penguin, Spheniscus demersus, as represented by the cochlear potentials. Proceedings of the National Academy of Sciences, 63(3), 676-680.

Wilson, M., \& Cook, P. F. (2016). Rhythmic entrainment. Why humans want to, fireflies can't help it, pet birds try, and sea lions have to be bribed. Psychonomic Bullitan Review,1-16.

Zarco, W., Merchant, H., Prado, L., \& Mendez, J. C. (2009). Subsecond timing in primates: comparison of interval production between human subjects and rhesus monkeys. Journal of Neurophysiology, 102(6), 3191-3202.

Žydelis, R., Small, C., \& French, G. (2013). The incidental catch of seabirds in gillnet fisheries: A global review. Biological Conservation, 162, 76-88. 
Table 1

Subject Information

\begin{tabular}{|c|c|c|c|c|c|c|c|}
\hline ID \# & Name & Sex & Side of Tie & Color of Tie & Adult/Juv & Age & Ave Weight $(\mathrm{Kg})$ \\
\hline 1869 & Herbie & $\mathrm{M}$ & Right & Dark Blue & Adult & 21 & 3.01 \\
\hline 1976 & Blanca & M & Left & Gray/Purple & Adult & 20 & 3.12 \\
\hline 1962 & Sydney & M & Left & Yellow & Adult & 20 & 3.12 \\
\hline 2061 & Liberace $^{\circ 0}$ & M & Left & Gray & Adult & 23 & 3.22 \\
\hline 2062 & Burns & M & Left & Red & Adult & 21 & 2.63 \\
\hline 2063 & Fred & M & Left & Light Blue & Adult & 21 & 3.96 \\
\hline 2065 & Judy & $\mathrm{F}$ & Right & Light Blue & Adult & 21 & 3.39 \\
\hline 2290 & Ricky $^{\circ}$ & M & Left & Orange & Adult & 16 & 3.42 \\
\hline 2310 & Tonic & $\mathrm{F}$ & Right & Pink & Adult & 16 & 2.86 \\
\hline 2336 & Vincent & $\mathrm{F}$ & Right & Red & Adult & 15 & 3.53 \\
\hline 2433 & Ash* & $\mathrm{F}$ & Right & Orange & Adult & 12 & 2.80 \\
\hline 2546 & Johnny $\mathrm{B}^{\circ \circ}$ & M & Left & Dark Green & Adult & 10 & 3.20 \\
\hline 2555 & Piccolo** & $\mathrm{F}$ & Right & Gray & Adult & 10 & 2.79 \\
\hline 2569 & Twiggy** & $\mathrm{F}$ & Right & Dark Green & Adult & 10 & 2.30 \\
\hline 2822 & Phoenix ${ }^{\circ 00}$ & M & Left & Light Green & Adult & 7 & 3.73 \\
\hline 2823 & Dassen & $\mathrm{F}$ & Right & DK Purple & Adult & 7 & 3.33 \\
\hline 2915 & Georgia*** & $\mathrm{F}$ & Right & Light Green & Adult & 6 & 2.98 \\
\hline 3071 & Sam & M & Left & Pink & Adult & 5 & 3.11 \\
\hline 2741 & Mitchell & M & Left & Purple & Adult & 8 & 3.13 \\
\hline 3128 & Pebbles & $\mathrm{F}$ & Right & Yellow & Adult & 4 & 3.13 \\
\hline 2203 & Durban & M & Left & DK Purple & Adult & 17 & 2.85 \\
\hline 3266 & Smeagol & $\mathrm{F}$ & Right & Purple & Adult & 2 & 2.68 \\
\hline 3399 & Gizmo & M & Left & White/Red & Adult & 1 & 3.37 \\
\hline 3400 & Blue & M & Right & White/Red & Adult & 1 & 3.04 \\
\hline 3401 & Obi & M & Left & Gray/Black & Adult & 1 & 3.06 \\
\hline 3402 & Sky & $\mathrm{F}$ & Right & Gray/Black & Adult & 1 & 2.53 \\
\hline 3404 & Marvel & M & Left & Green Tie & Adult & 1 & 3.31 \\
\hline 3403 & Swoop & $\mathrm{F}$ & Right & Green Tie & Adult & 1 & 2.65 \\
\hline 3467 & Toad & M & Left & Brown Tie & Juvenile & 0 & 3.05 \\
\hline 3485 & Oscar & M & Left & Green/White & Juvenile & 0 & 2.91 \\
\hline 3502 & Lena & $\mathrm{F}$ & N/A & N/A & Juvenile & 0 & 3.06 \\
\hline
\end{tabular}

Note. Asterisks represent one $(*)$, two $(* *)$ or three $(* * *)$ chicks hatched by female penguins throughout the duration of the study. Open circles $\left(^{\circ}\right)$ represent the number of chicks born to each father in a mated pair with chicks over the duration of the study. 
Table 2

Ethogram Behaviors

Behavior Description

Standing Penguins stands upright with its head pointing straight ahead $\left(0^{\circ}\right)$ either perpendicular to its body or tilted $45^{\circ}$ upward.

Laying down $\quad$ Penguin lays down with its head pointing straight ahead $\left(0^{\circ}\right)$

Walking Penguin travels from one destination to another with a slight rocking motion of $20^{\circ}$ to the left and right

Playing with toys Penguin interacts with a toy using its beak

Defecating

Penguin expels white liquid from its posterior with a forceful motion

In Den Penguin is in its den, out of view of the camera

Grooming Penguin scratches its body with its beak or foot, shakes its head body or tail, or flaps its wings forcefully

Head turn Penguin turns its head at least $45^{\circ}$ to the left or right of the center axis of its body

Looking at floor Penguin bends over until it is within a beak's distance of the floor and moves its head in a scanning motion ranging from $45^{\circ}$ to $180^{\circ}$

Vocalizing Penguin tilts its head upward at an angle of at least $45^{\circ}$, opens its beak and emits sound

Pecking Penguin pecks another animal's beak or body, sometimes accompanied with a chasing behavior.

Watching Penguin's head motion closely follows the motion of an animal within 1.5 body lengths from the focal bird

Running from Penguin runs from an animal pecking or chasing them chaser 
Beak jousting Two penguins stand beak to beak and guide each other's head with their beak

Swimming Penguin propels its self with its wings, with its head either submerged or up and out of the water

Drinking Penguin leans over and pecks at the water pool using its beak

Note. The behaviors represented in the table were observed most frequently, by the majority of birds. Other less frequent behaviors are not included. 
Table 3

Pilot Study Stage 1 Sessions

\begin{tabular}{ccc}
\hline Date & Pilot Stage & Speaker \\
\hline $11 / 17 / 16$ & Stages 1a \& 1b & No \\
$11 / 19 / 16$ & Stages 1a \& 1b & No \\
$12 / 8 / 16$ & Stages 1a \& 1b & No \\
$12 / 10 / 16$ & Stage 1c & Yes \\
$12 / 15 / 16$ & Stage 1c & Yes \\
$1 / 5 / 17$ & Stage 1c & Yes \\
\hline
\end{tabular}


Table 4

Pilot Study Stage 2 \& 3 Sessions

\begin{tabular}{cccccc}
\hline Date & Sound Played & Times & & Inter-trial & \\
Played & Duration & Interval & Loudness \\
\hline $1 / 7 / 17$ & Alphabet & 5 & 10 & 30 & 70 \\
$1 / 7 / 17$ & Alphabet & 5 & 10 & 60 & $70^{*}$ \\
$1 / 7 / 17$ & SPZ Penguins & 5 & 10 & 60 & $70^{*}$ \\
$1 / 12 / 17$ & SPZ Penguins & 10 & 10 & 60 & 70 \\
$1 / 12 / 17$ & Wind chimes & 10 & 10 & 60 & 70 \\
$1 / 14 / 17$ & Wind chimes & 10 & 10 & 60 & 70 \\
$1 / 14 / 17$ & Alphabet & 10 & 10 & 60 & 70 \\
$1 / 17 / 17$ & Alphabet & 10 & 10 & 60 & 70 \\
$1 / 17 / 17$ & Chick Peep & 10 & 10 & 60 & 70 \\
$1 / 19 / 17$ & Isochronous & 10 & 10 & 30 & 70 \\
$1 / 21 / 17$ & Isochronous & 10 & 10 & 30 & 70 \\
$1 / 21 / 17$ & Long-short & 10 & 10 & 30 & 70 \\
$1 / 21 / 17$ & Hierarchical & 10 & 10 & 30 & 70 \\
$1 / 24 / 17$ & Hierarchical & 6 & 10 & 30 & 70 \\
$1 / 24 / 17$ & Long-short & 3 & 10 & 30 & 70 \\
$1 / 24 / 17$ & Isochronous & 3 & 10 & 30 & 70 \\
$1 / 26 / 17$ & Hierarchical & 1 & 10 &. & 70 \\
$1 / 26 / 17$ & Charge & 3 & 10 & 30 & 70 \\
\hline
\end{tabular}

Note. On sessions marked with asterix (*) the base loudness was $70 \mathrm{~dB}$ re $20 \mu \mathrm{Pa}$, but the volume was increased by 2 notches on the iPhone. 
Table 5

Test Session Composition

\begin{tabular}{|c|c|c|c|}
\hline Stimulus Group & Familiar Stimulus & Novel Stimulus & First Test Trial \\
\hline \multirow[t]{6}{*}{ Charge First } & Charge & Hierarchical & Familiar \\
\hline & Charge & Hierarchical & Novel \\
\hline & Charge & Isochronous & Familiar \\
\hline & Charge & Isochronous & Novel \\
\hline & Charge & Long-short & Familiar \\
\hline & Charge & Long-short & Novel \\
\hline \multirow[t]{6}{*}{ Hierarchical First } & Hierarchical & Charge & Familiar \\
\hline & Hierarchical & Charge & Novel \\
\hline & Hierarchical & Isochronous & Familiar \\
\hline & Hierarchical & Isochronous & Novel \\
\hline & Hierarchical & Long-short & Familiar \\
\hline & Hierarchical & Long-short & Novel \\
\hline \multirow[t]{6}{*}{ Isochronous First } & Isochronous & Charge & Familiar \\
\hline & Isochronous & Charge & Novel \\
\hline & Isochronous & Hierarchical & Familiar \\
\hline & Isochronous & Hierarchical & Novel \\
\hline & Isochronous & Long-short & Familiar \\
\hline & Isochronous & Long-short & Novel \\
\hline \multirow[t]{6}{*}{ Long-short First } & Long-short & Charge & Familiar \\
\hline & Long-short & Charge & Novel \\
\hline & Long-short & Hierarchical & Familiar \\
\hline & Long-short & Hierarchical & Novel \\
\hline & Long-short & Isochronous & Familiar \\
\hline & Long-short & Isochronous & Novel \\
\hline
\end{tabular}


Table 6

Inter-Rater Reliability Check

\begin{tabular}{cccc}
\hline & \multicolumn{3}{c}{ Head Turns Counted } \\
Session & First Coder & Second Coder & Agreement \\
\hline 4 & 101 & 88 & $87 \%$ \\
5 & 130 & 120 & $92 \%$ \\
9 & 53 & 66 & $80 \%$ \\
10 & 103 & 87 & $84 \%$ \\
13 & 59 & 60 & $98 \%$ \\
19 & 183 & 148 & $81 \%$ \\
20 & 134 & 150 & $89 \%$ \\
Overall & 665 & 763 & $87 \%$ \\
\hline
\end{tabular}

Note. The experimenter was the first coder. An additional session was coded however, the agreement rate was very low $(52 \%)$ as the second coder made an error and coded a different penguin than the experimenter. The experimenter recoded this session and the agreement was $87 \%$. 
Table 7

Test Session Information

\begin{tabular}{|c|c|c|c|c|c|}
\hline Date & Familiar & Novel & First & Habituation & $\mathrm{n}=$ \\
\hline $1 / 31 / 17$ & Isochronous & Long-short & Familiar & Yes* & 5 \\
\hline $2 / 2 / 17$ & Hierarchical & Isochronous & Novel & Yes & 7 \\
\hline $2 / 4 / 17$ & Charge & Hierarchical & Familiar & No & 7 \\
\hline $2 / 7 / 17$ & Long-short & Isochronous & Novel & Yes & 4 \\
\hline 2/9/17 & Long-short & Hierarchical & Novel & No & 9 \\
\hline $2 / 16 / 17$ & Hierarchical & Long-short & Familiar & No & 8 \\
\hline $2 / 21 / 17$ & Isochronous & Hierarchical & Novel & Yes & 8 \\
\hline $2 / 23 / 17$ & Isochronous & Charge & Familiar & Yes & 4 \\
\hline $2 / 25 / 17$ & Hierarchical & Isochronous & Familiar & Yes* & 5 \\
\hline $2 / 28 / 17$ & Charge & Long-short & Novel & No & 5 \\
\hline $3 / 2 / 17$ & Long-short & Charge & Novel & No & 7 \\
\hline $3 / 4 / 17$ & Charge & Long-short & Familiar & No & 4 \\
\hline $3 / 7 / 17$ & Isochronous & Charge & Novel & Yes & 6 \\
\hline $3 / 16 / 17$ & Long-short & Isochronous & Familiar & No & 9 \\
\hline $3 / 18 / 17$ & Hierarchical & Long-short & Familiar & No & 4 \\
\hline $3 / 21 / 17$ & Isochronous & Hierarchical & Novel & No & 6 \\
\hline $3 / 23 / 17$ & Hierarchical & Charge & Novel & No & 11 \\
\hline $3 / 25 / 17$ & Charge & Isochronous & Familiar & No & 11 \\
\hline $3 / 28 / 17$ & Long-short & Hierarchical & Familiar & No & 7 \\
\hline $3 / 30 / 17$ & Charge & Hierarchical & Novel & No & 6 \\
\hline $4 / 1 / 17$ & Isochronous & Long-short & Novel & Yes & 6 \\
\hline $4 / 4 / 17$ & Hierarchical & Charge & Familiar & No & 7 \\
\hline $4 / 6 / 17$ & Long-short & Charge & Familiar & Yes & 7 \\
\hline $4 / 8 / 17$ & Charge & Isochronous & Familiar & No & 5 \\
\hline
\end{tabular}

Note. Habituation criterion was met when the average of the last three familiarization trials were less than half of the average of the first three familiarization trials. The session marked with an asterisk (*), the average of the last three familiarization trials was exactly $50 \%$ of average of the first three trials. The column labeled "first" indicated whether the novel or familiar stimulus was played first in the test trials. The column labeled " $n$ " indicates how many birds were observed in any given session. The rows are color coded based on which stimulus was played during familiarization trials. 
Table 8

Descriptive Statistics for the Final Three Familiarization Trials and the First Novel Test Trials

\begin{tabular}{lccc}
\hline \multicolumn{1}{c}{ Condition } & Total Sessions & $\begin{array}{c}\text { Familiarization } \\
\text { Trials 8-10 }\end{array}$ & Novel Test 1 \\
\hline All Sessions & 24 & $0.90 \pm 0.34$ & $1.18 \pm 0.53$ \\
Habituated Sessions & 9 & $2.13 \pm 0.82$ & $1.26 \pm 0.67$ \\
Non-Habituated Sessions & 15 & $3.04 \pm 1.01$ & $1.29 \pm 0.45$ \\
Familiarized to Isochronous & 4 & $1.90 \pm 0.75$ & $1.22 \pm 0.63$ \\
Familiarized to Long-short & 4 & $1.12 \pm 0.46$ & $1.47 \pm 0.46$ \\
Familiarized to Hierarchical & 4 & $2.65 \pm 1.14$ & $0.80 \pm 0.34$ \\
Familiarized to Charge & 4 & $3.24 \pm 0.70$ & $1.24 \pm 0.54$ \\
\hline
\end{tabular}

Note. The table shows means and standard deviations for head turns per bird in all conditions. 


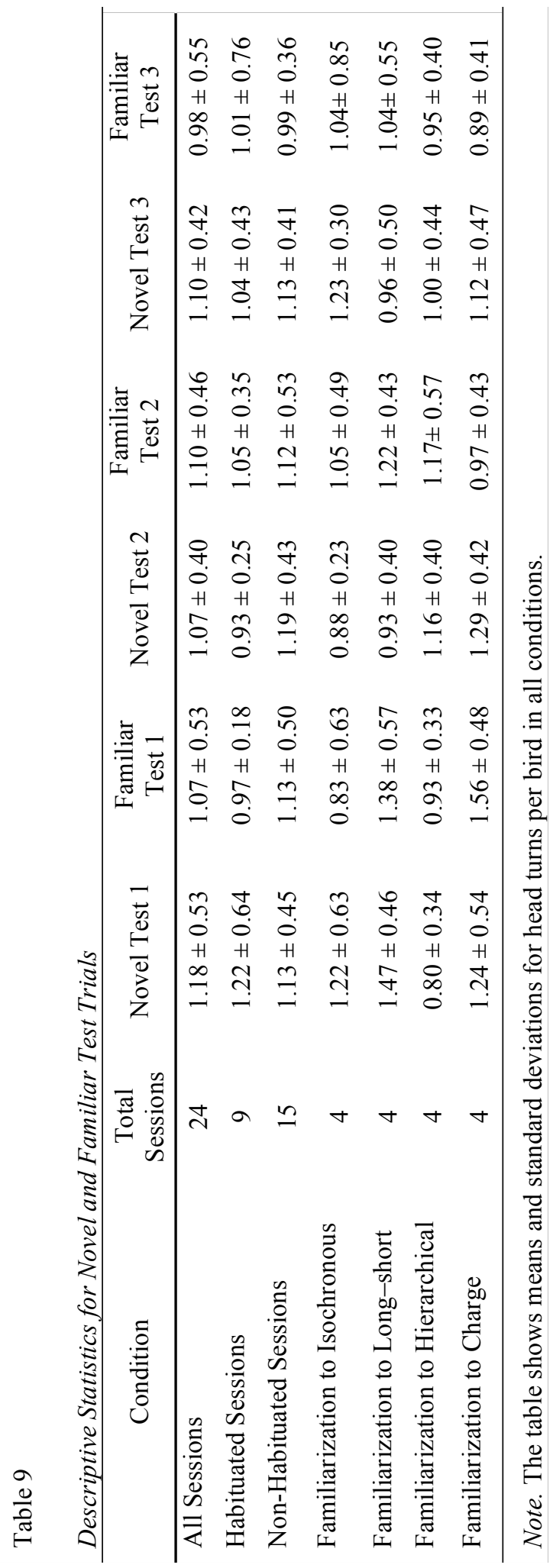


Table 10

Descriptive Statistics for the Novel Test Trials and the Familiar Test Trials

\begin{tabular}{lccc}
\hline \multicolumn{4}{c}{ Descriptive Statistics for the Novel Test Trials and the Familiar Test Trials } \\
\multicolumn{1}{|c}{ Condition } & $\begin{array}{c}\text { Total } \\
\text { Sessions }\end{array}$ & $\begin{array}{c}\text { Average of } \\
\text { Novel Test } \\
\text { Trials }\end{array}$ & $\begin{array}{c}\text { Average of Familiar Test } \\
\text { Trials }\end{array}$ \\
\hline All Sessions & 24 & $1.11 \pm 0.33$ & $1.05 \pm 0.40$ \\
Habituated Sessions & 9 & $1.07 \pm 0.33$ & $1.01 \pm 0.49$ \\
Non-Habituated Sessions & 15 & $1.15 \pm 0.32$ & $1.08 \pm 0.33$ \\
Familiarization to Isochronous & 4 & $1.11 \pm 0.28$ & $0.97 \pm 0.58$ \\
Familiarization to Long-short & 4 & $1.12 \pm 0.39$ & $1.21 \pm 0.42$ \\
Familiarization to Hierarchical & 4 & $0.99 \pm 0.32$ & $1.02 \pm 0.35$ \\
Familiarization to Charge & 4 & $1.21 \pm 0.35$ & $1.01 \pm 0.24$ \\
\hline
\end{tabular}

Note. The table shows means and standard deviations for head turns per bird in all conditions. 
Table 11

Post Hoc Contrasts for Head Turns per Bird in the ANOVA run on Test Trials

\begin{tabular}{llll}
\hline \multicolumn{1}{c}{ Effect } & \multicolumn{1}{c}{ Level } & $M$ & $95 \% C I$ \\
\hline \multirow{2}{*}{ Habituation Criterion } & Criterion Met & 1.03 & $(0.88,1.18)$ \\
& Criterion Not Met & 1.11 & $(1.00,1.22)$ \\
Familiarization & Charge & & \\
Rhythm & Hierarchical & 1.07 & $(0.77,1.37)$ \\
& Isochronous & 0.99 & $(0.73,1.25)$ \\
Long-short & 1.07 & $(0.79,1.34)$ \\
Trial Type & & 1.15 & $(0.90,1.41)$ \\
& Novel & & \\
Frial Number & 1 & 1.10 & $(0.98,1.22)$ \\
& 2 & 1.04 & $(0.92,1.16)$ \\
& 3 & & $(0.92,1.32)$ \\
& & 1.12 & $(0.88,1.28)$ \\
& & 1.08 & $(0.90,1.41)$ \\
\hline
\end{tabular}



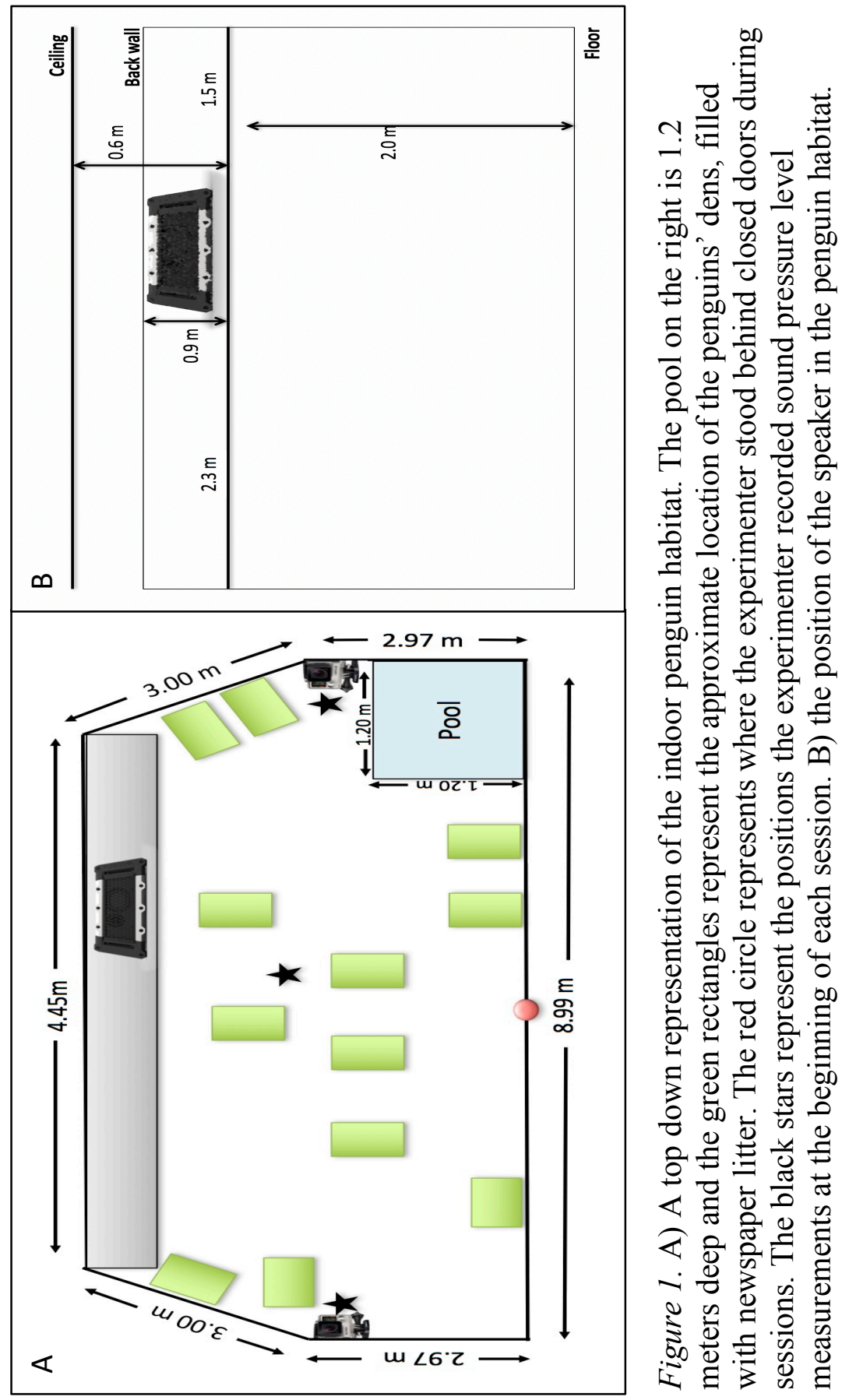


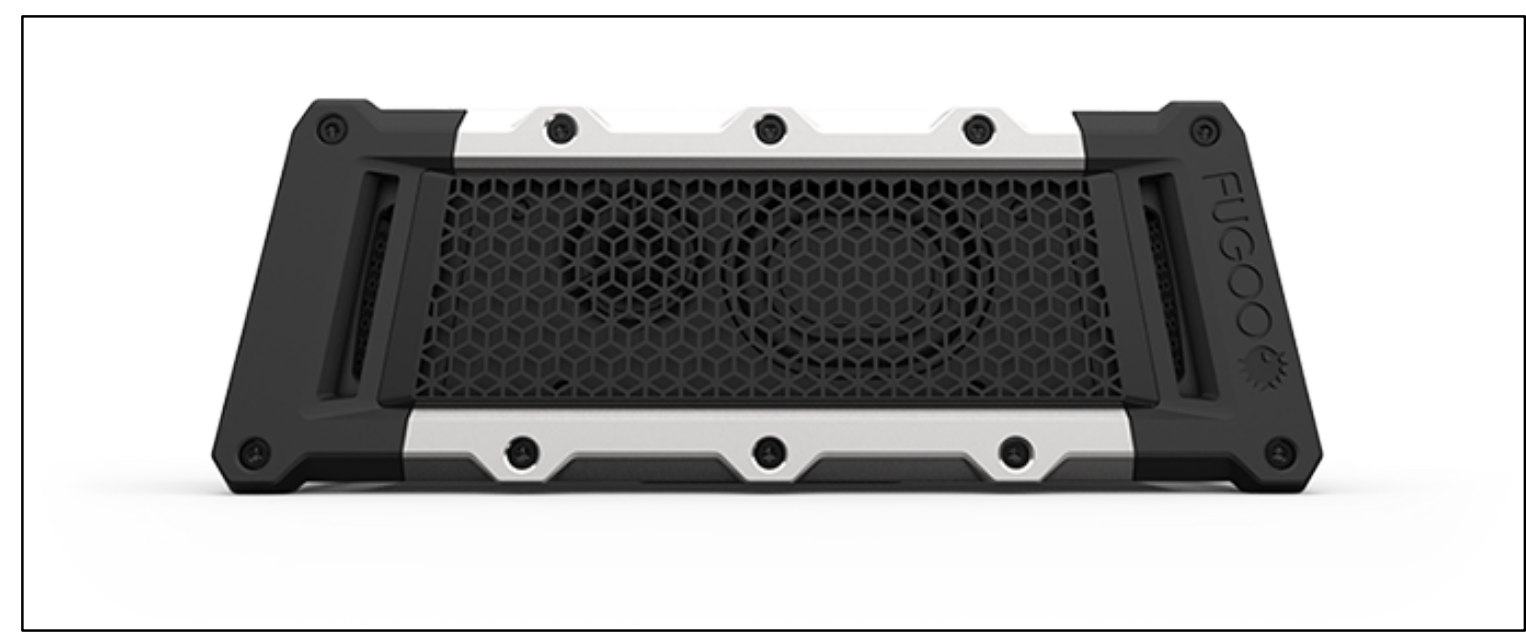

Figure 2. The FUGOO Tough Speaker is a waterproof, shockproof in-air speaker with six symmetrically placed drivers. Its dimensions are 61 x 198 x $73 \mathrm{~mm}$ and weighs $643 \mathrm{~g}$. The speaker has two tweeters to deliver high frequency sounds, two mid/woofer drivers for midfrequency sounds and two passive radiators to deliver low-frequency sounds. The FUGOO Tough has a frequency range of $60 \mathrm{~Hz}$ to $20 \mathrm{kHz}$. The speaker has a battery life of 40 hours and has BlueTooth 4.0 wireless connectivity of up to $10 \mathrm{~m}$ (http://www.fugoo.com/fugootough/\#prodTech). 


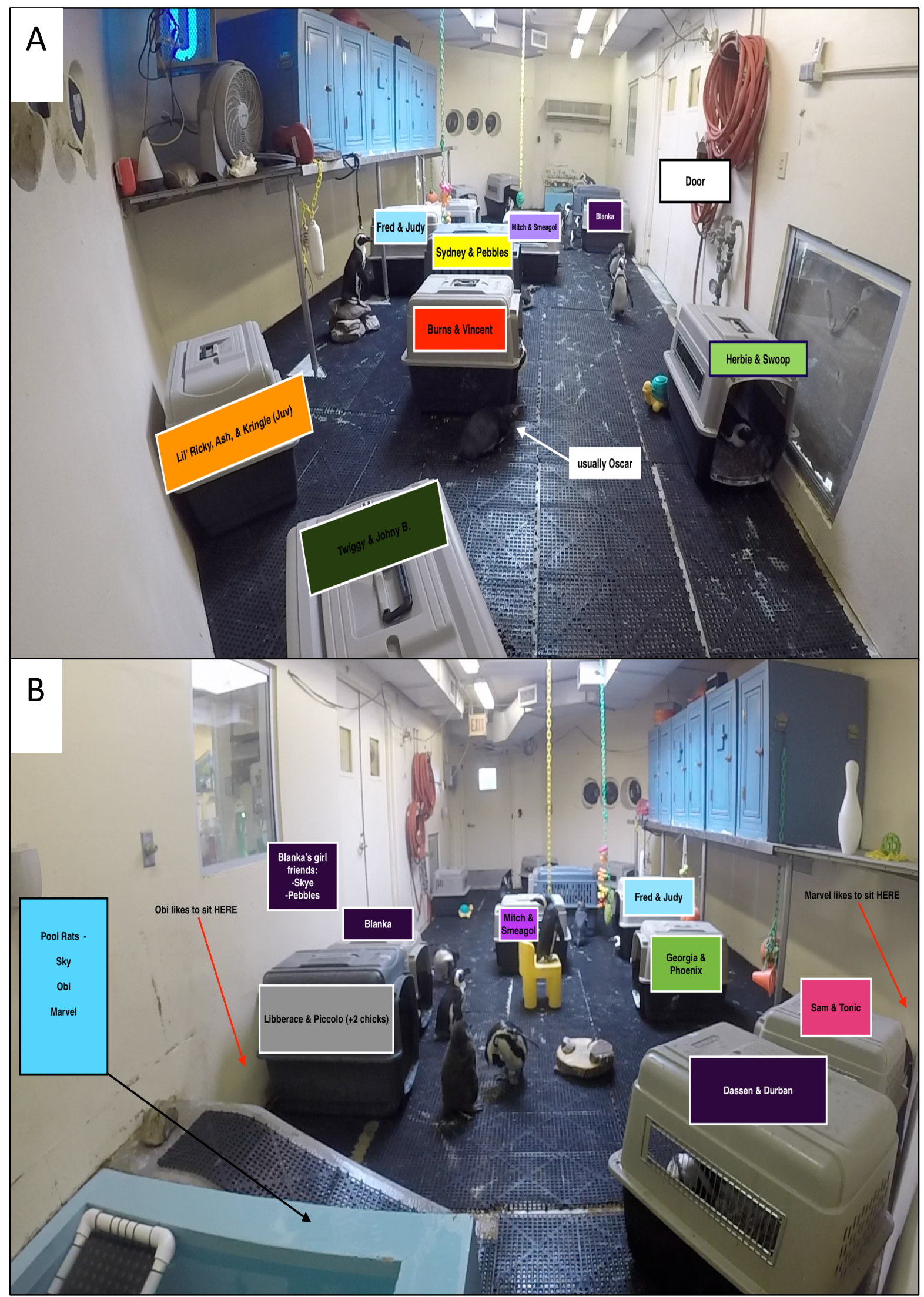

Figure 3. The indoor view of the indoor penguin habitat from A) Camera 1 and B) Camera 2. The labels depict where penguins normally stand during sessions. 


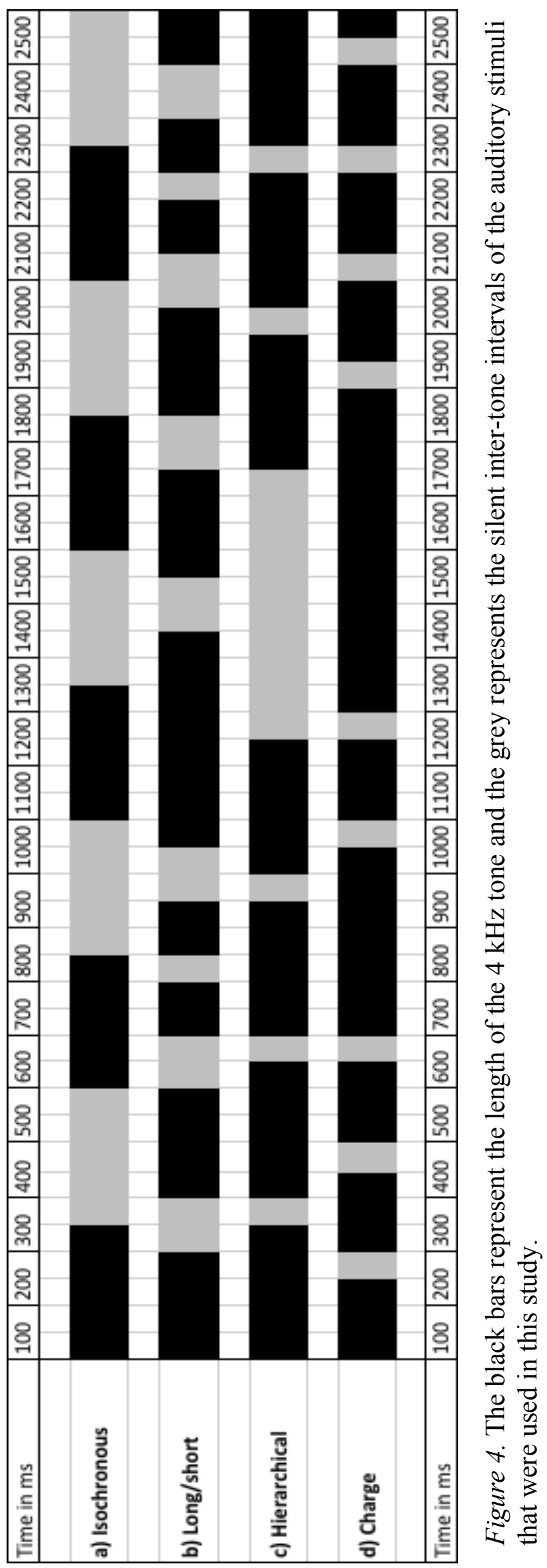




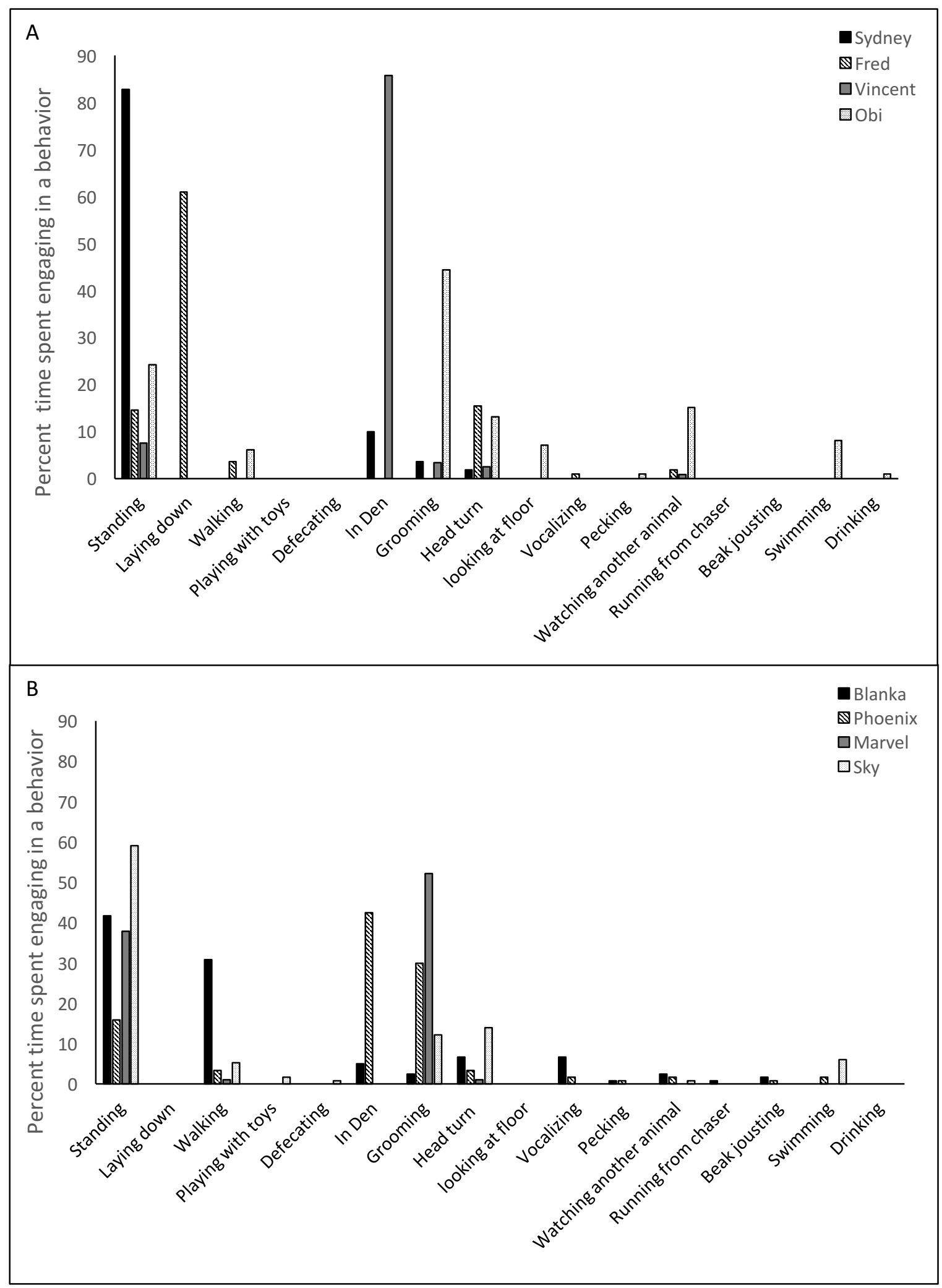

Figure 5. Percentage of time engaged in various behaviors A) before the introduction of the speaker and B) after the introduction of the speaker is in the pilot study. Note, the penguins that were visible in A and B are not the same animals. The birds observed in this figure were those visible for the entire 30 minutes. 


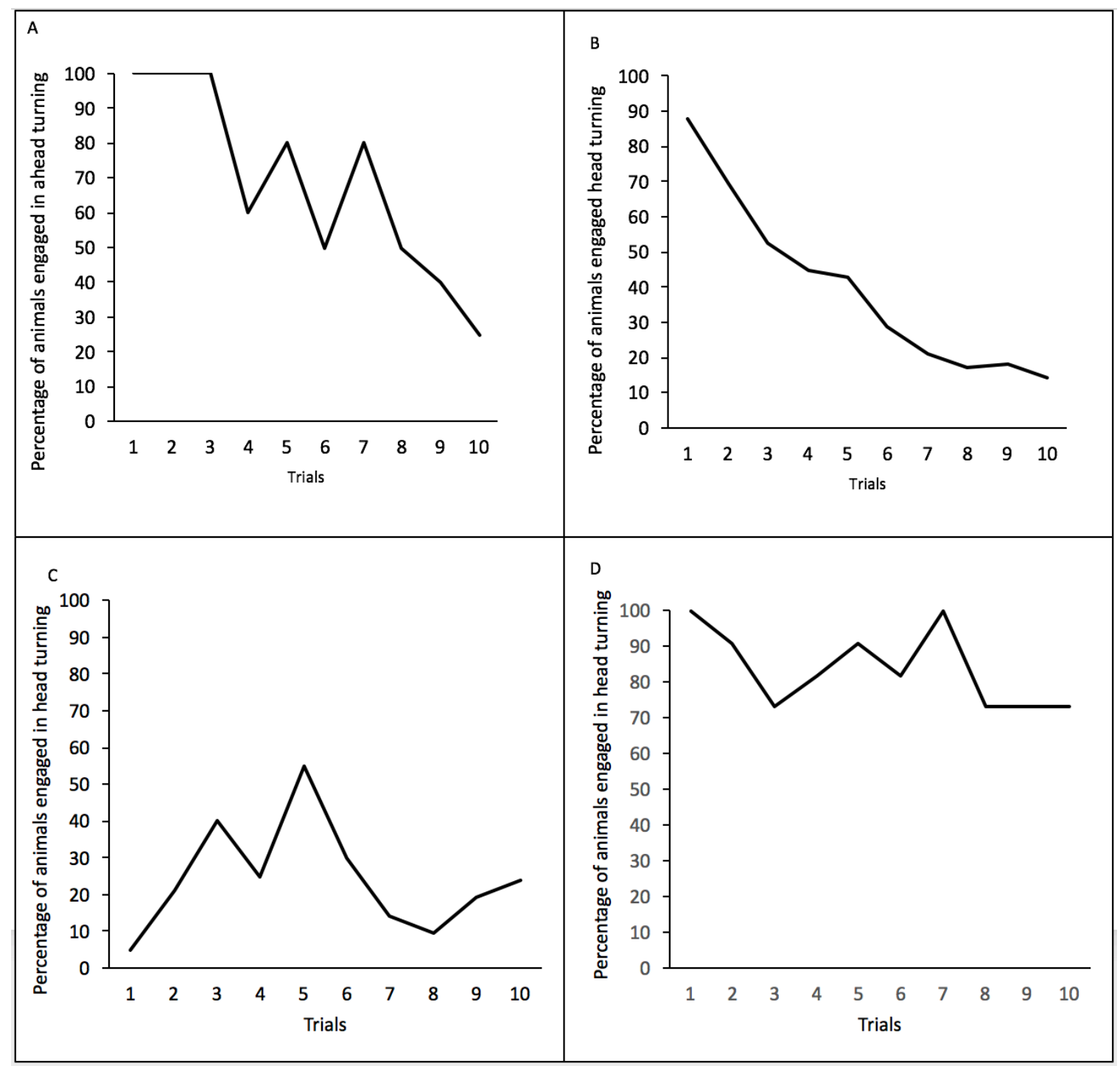

Figure 6. The percentage of animals visible to the camera engaging in head turning during ten trials of A) an ecstatic display song from African penguins at the Seneca Park Zoo and B) a female voice speaking the alphabet, C) wind chimes and D) wild African penguin chick vocalizations. 


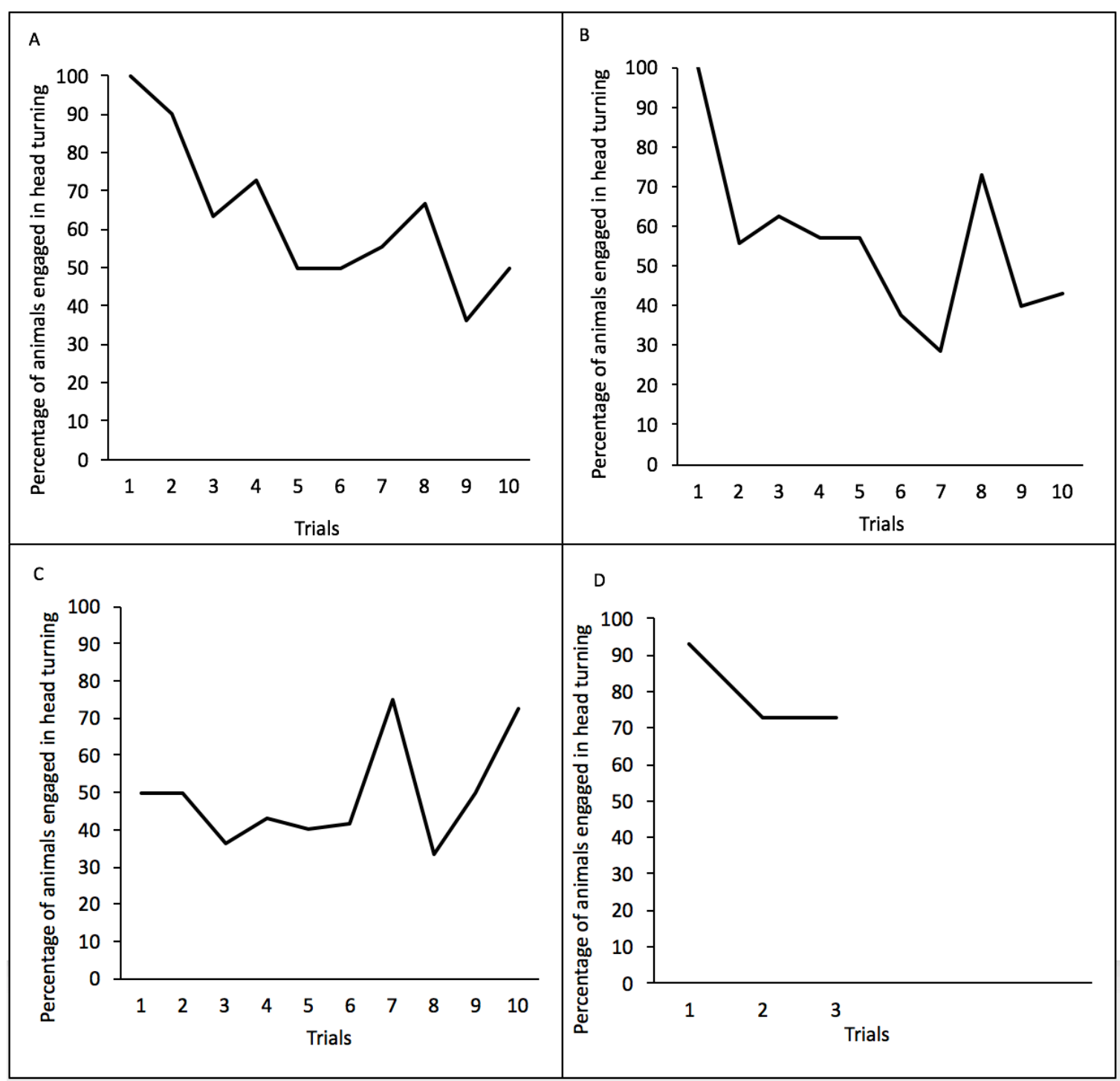

Figure 7. The percentage of animals visible to the camera engaged in head turning during the presentation of ten trials of A) the Isochronous test stimulus, B) the Longshort test stimulus, C) the Hierarchical stimulus and D) the Charge Stimulus. The Charge stimulus was only played for three trials. 


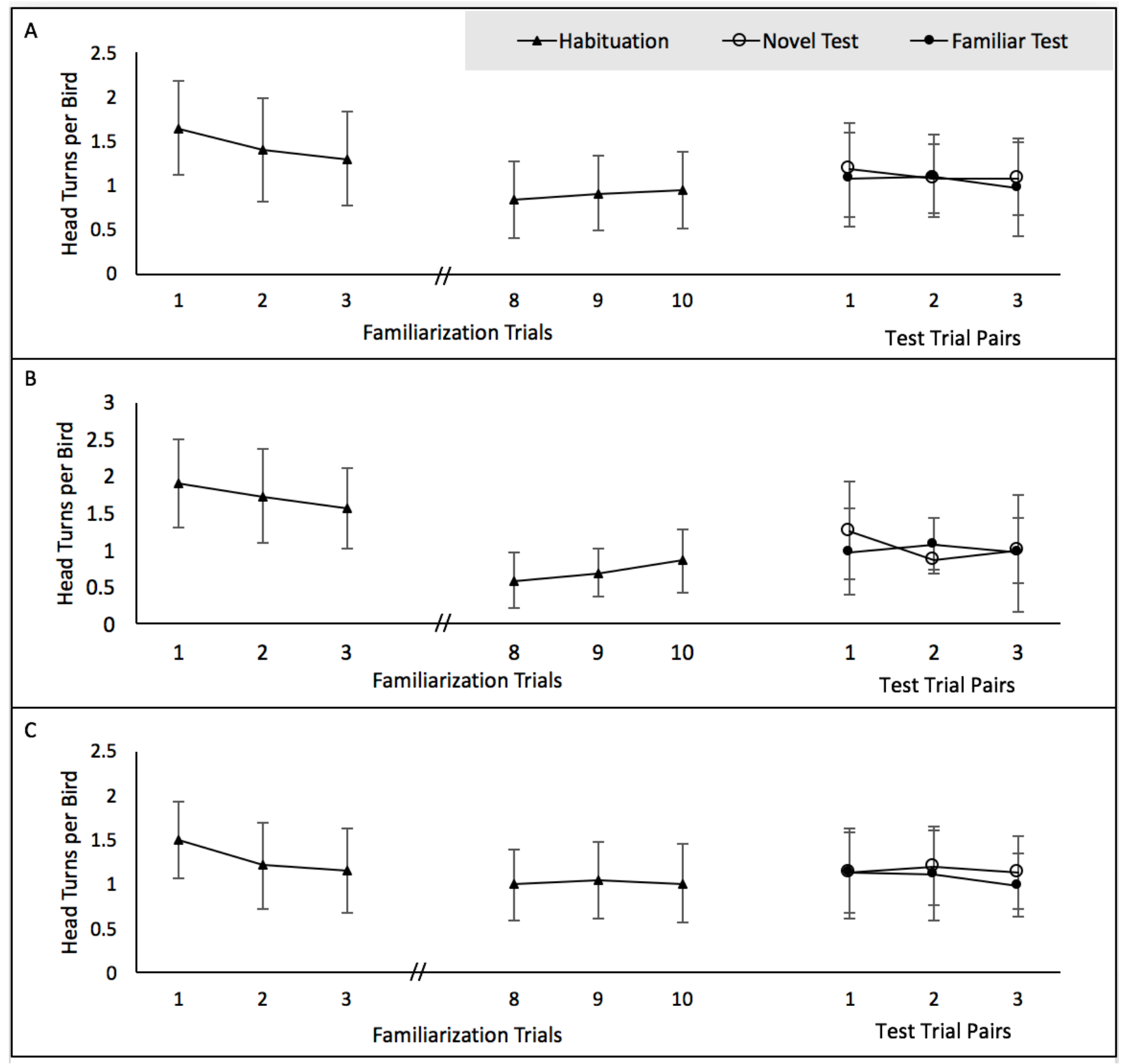

Figure 8. Head turns per bird for habituation and test trials in A) all twenty-four sessions, B) all nine sessions where the penguins met the habituation criterion and C) all fifteen sessions where penguins did not meet habituation criterion. Error bars mark the standard deviation of the mean. 


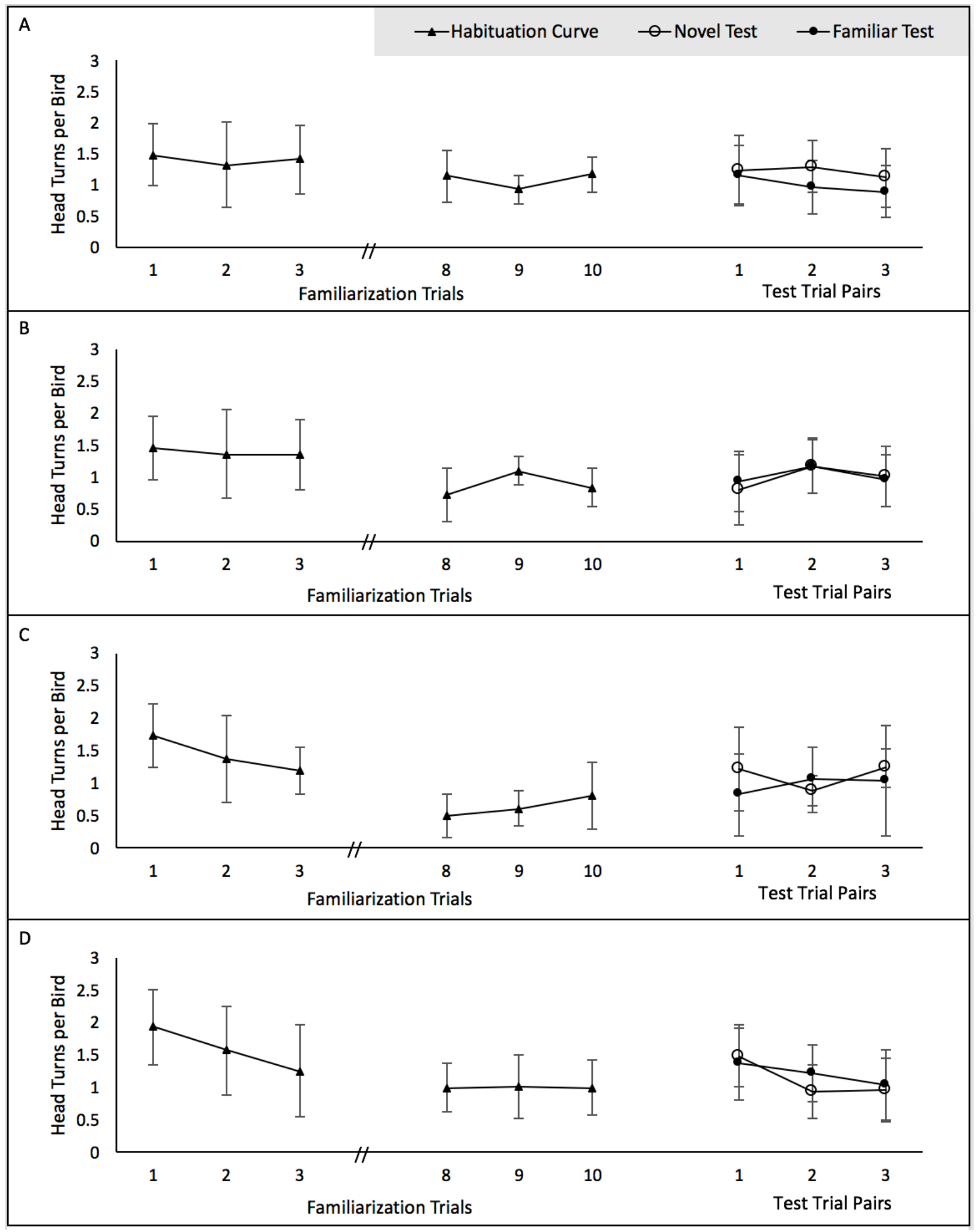

Figure 9. Head turns per bird for habituation and test trials in A) sessions where Charge was the familiarization stimulus B) sessions where Hierarchical was the familiarization stimulus, C) sessions where Isochronous was the familiarization stimulus, and D) sessions where Longshort was the familiarization stimulus. Error bars mark the standard deviation of the mean. 


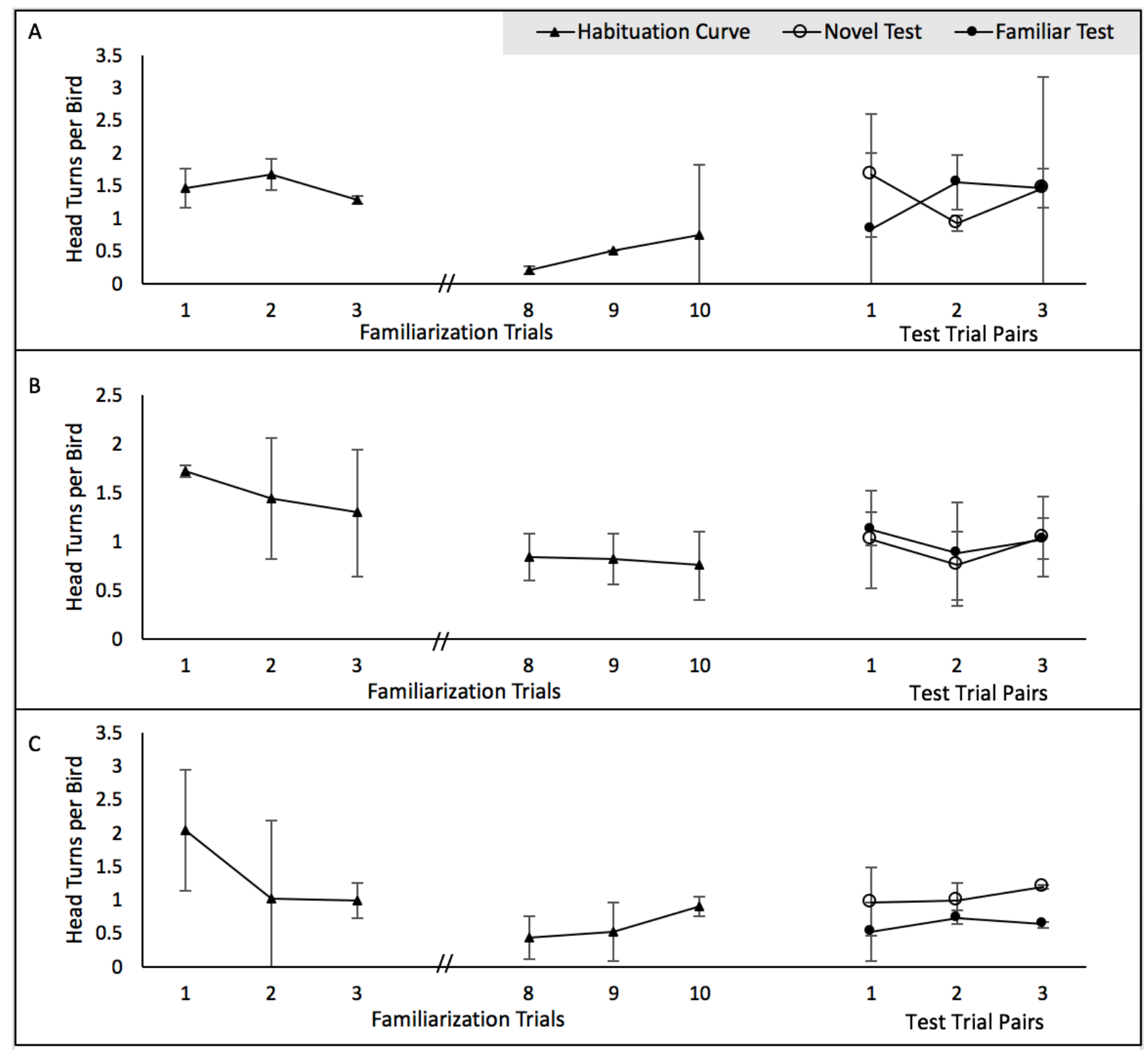

Figure 10. All sessions where Isochronous was the familiarization stimulus. A) the two sessions with Isochronous as the familiarization stimulus and Charge as the novel stimulus B) the two sessions with Isochronous as the familiarization stimulus and Hierarchical as the novel stimulus, and C) the two sessions with Isochronous as the familiarization stimulus and Long-short as the novel stimulus. Error bars mark the standard deviation of the mean. 


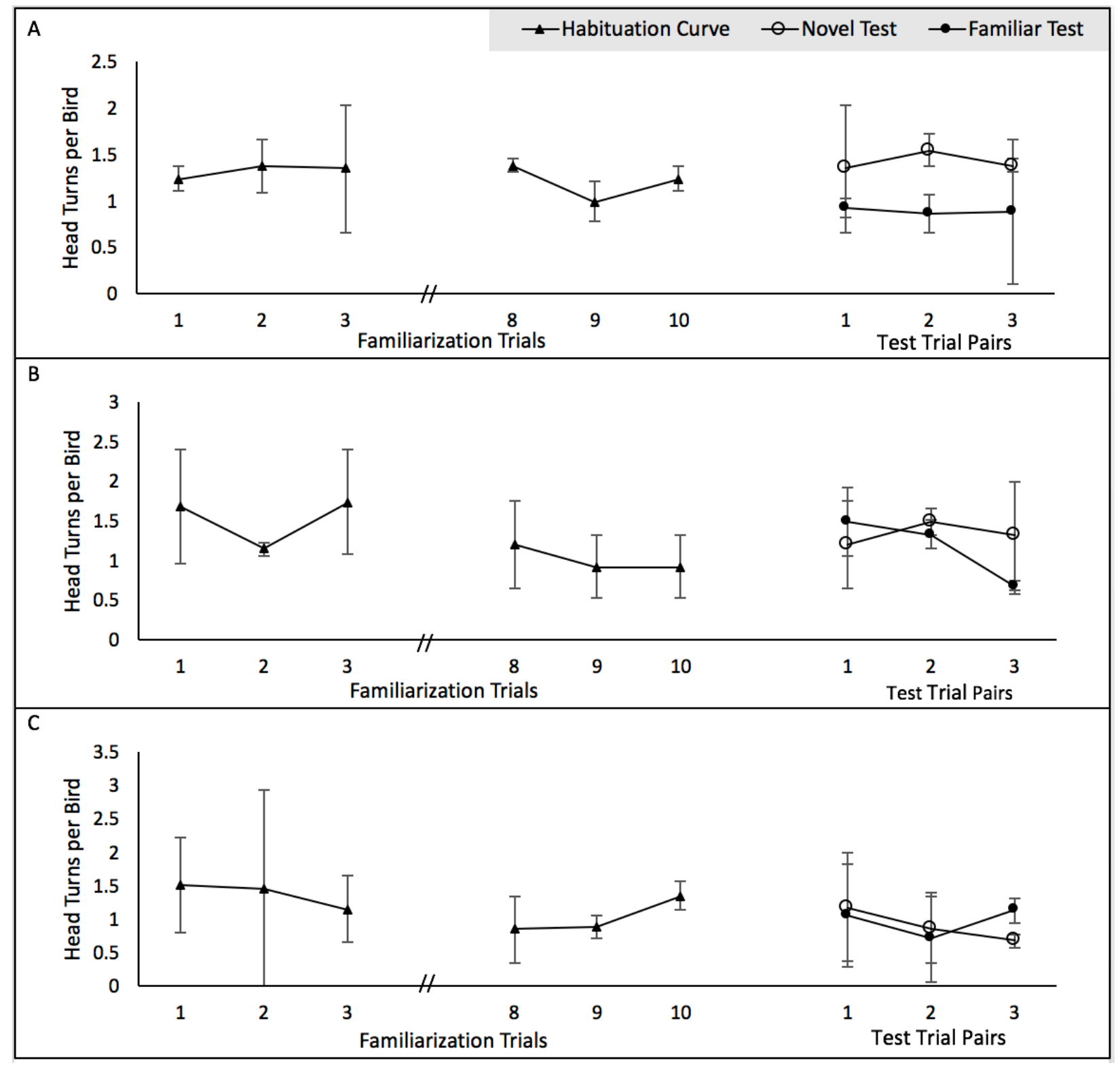

Figure 11. All sessions where Charge was the familiarization stimulus. A) the two sessions with Charge as the familiarization stimulus and Hierarchical as the novel stimulus B) the two sessions with Charge as the familiarization stimulus and Isochronous as the novel stimulus, and C) the two sessions with Charge as the familiarization stimulus and Long-short as the novel stimulus. Error bars mark the standard deviation of the mean. 


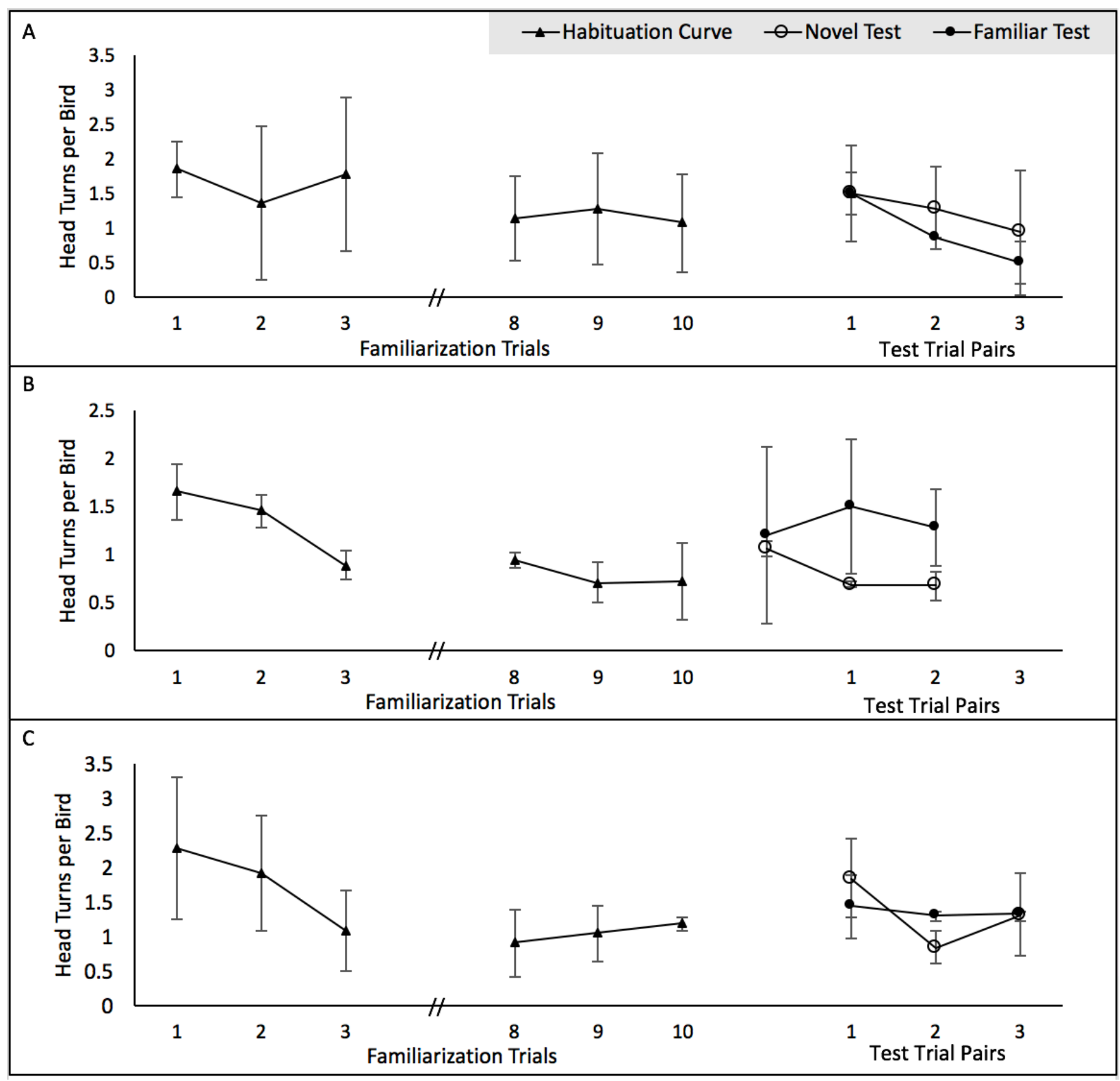

Figure 12. All sessions where Long-short was the familiarization stimulus. A) the two sessions with Long-short as the familiarization stimulus and Charge as the novel stimulus B) the two sessions with Long-short as the familiarization stimulus and Hierarchical as the novel stimulus, and $\mathrm{C}$ ) the two sessions Long-short as the familiarization stimulus and Isochronous as the novel stimulus. Error bars mark the standard deviation of the mean. 


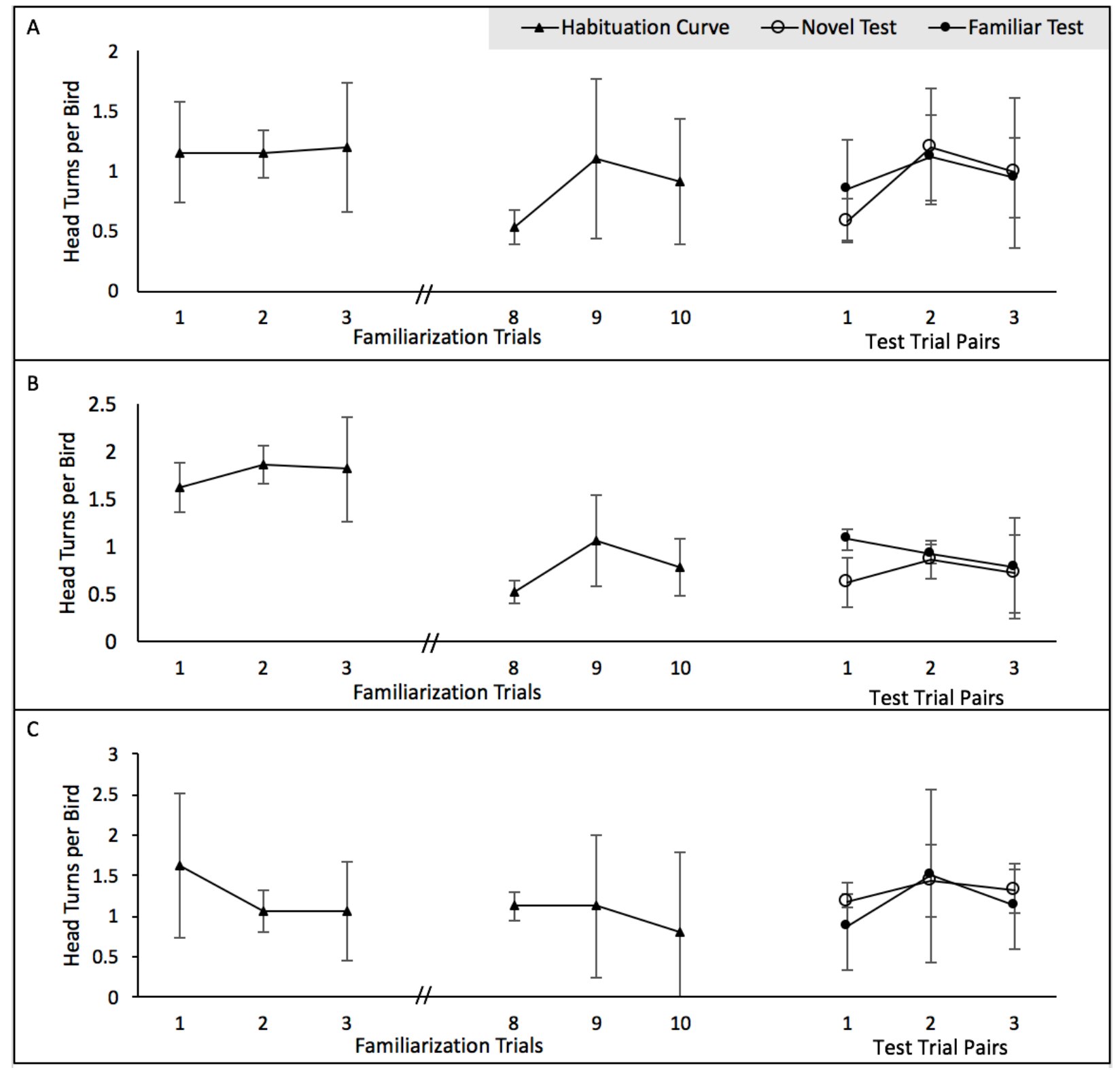

Figure 13. All sessions where Hierarchical was the familiarization stimulus. (A) the two sessions with Hierarchical as the familiarization stimulus and Charge as the novel stimulus (B) the two sessions with Hierarchical as the familiarization stimulus and Isochronous as the novel stimulus, and (C) the two sessions Hierarchical as the familiarization stimulus and Long-short as the novel stimulus. Error bars mark the standard deviation of the mean. 


\section{Appendix}

\section{Instructions for How to Identify a Head Turn}

\section{What to count as a head turn:}

- The penguin's head is up, and they turn it at a $45^{\circ}$ rotation from the center axis or greater (you will often see $90^{\circ}$ or more) but $45^{\circ}$ is the minimum to count it as a head turn.

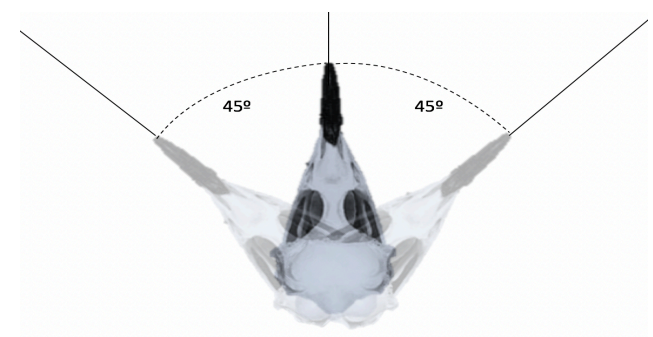

- If a bird is scratchi _ _le of at least $45^{\circ}$ then go back to scratching.

- If a bird is turning their head, PAUSES, and then goes down to scratch, count this.

- DO include birds lying down.

- DO include birds in their dens that you can see clearly (usually just Herbie and Swoop)

- DO include birds in their dens with their heads sticking out.

- DO include birds who are scratching, and LIFT THEIR HEAD, Pause, then return to scratching

- EACH MOVEMENT AWAY FROM THE CENTER AXIS IS COUNTED AS TURN (however, if the movements to get to $45^{\circ}$ or greater are twitchy, only count this as one turn, if the twitch is big enough to return the head to the center axis, it will be counted as two turns).

\section{What NOT to count as a head turn:}

- A twitch like movement to the left or right that is not at least $45^{\circ}$.

- When a bird is turning to scratch its self or another bird and DOES NOT PAUSE.

- When a bird is following the movements of another bird with their head, or going to peck another bird.

- When the bird is turning its head but its beak is pointed toward the ground.

- DON'T count when an animals head is off axis, like they are just sitting with their head to the right, but they do not recoil it back to the center.

- DON'T count when an animal is scratching, then returns its head upright (UNLESS, it pauses on the way up and has its head turned at least $45^{\circ}$ )

- DON'T count head shaking (like you would see a dog do after it got wet) this is a grooming behavior, not a response to stimuli. 